NU United States Department of Commerce National Institute of Standards and Technology

NISTIR 3947

\title{
IGNITION CHARACTERISTICS OF THE NICKEL-BASED ALLOY UNS N07001 IN PRESSURIZED OXYGEN
}

James W. Bransford

Phillip A. Billiard 



\section{NISTIR 3947}

\section{IGNITION CHARACTERISTICS OF THE NICKEL-BASED ALLOY UNS N07001 IN PRESSURIZED OXYGEN}

James W. Bransford

Phillip A. Billiard ${ }^{\dagger}$

Chemical Engineering Science Division

Center for Chemical Technology

National Measurement Laboratory

National Institute of Standards and Technology

Boulder, Colorado 80303-3328

†Boeing Company, Seattle, Washington

September 1990

Sponsored by

NASA/George C. Marshall Space Flight Center

George C. Marshall Space Flight Center, Alabama 35812

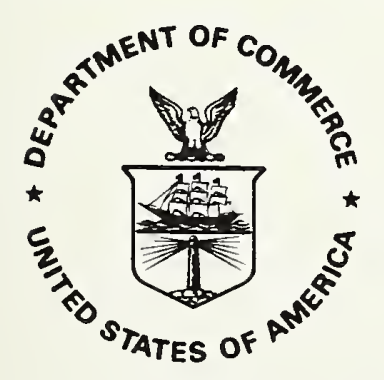

U.S. DEPARTMENT OF COMMERCE, Robert A. Mosbacher, Secretary NATIONAL INSTITUTE OF STANDARDS AND TECHNOLOGY, John W. Lyons, Director 

CONTENTS

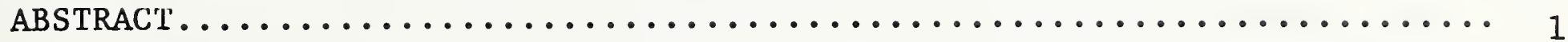

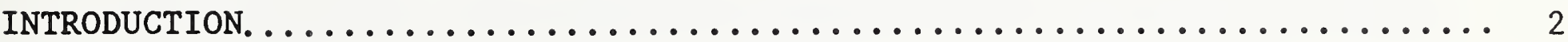

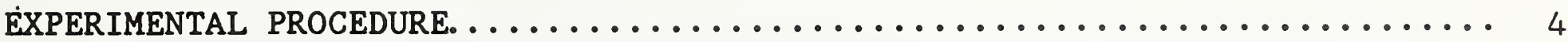

METAL IGNITION PROCESS. ............................... 10

RESULTS........................................ 20

1. Linear Temperature Scan Tests ........................ 20

2. Differential Thermal Analysis Studies.................. 25

3. Incremental Temperature Scan Tests .................... 29

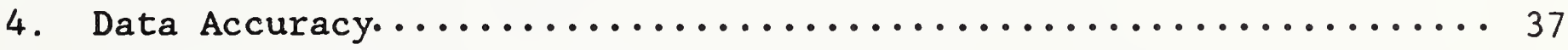

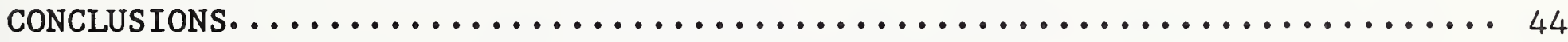

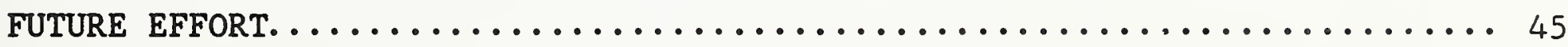

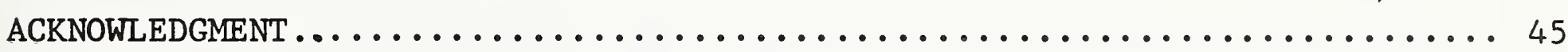

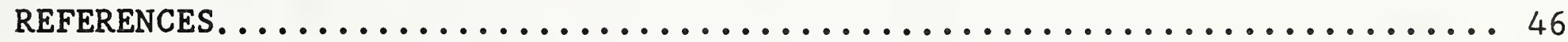


1. Test specimen configuration..$\ldots \ldots \ldots \ldots \ldots \ldots \ldots \ldots \ldots \ldots \ldots \ldots$

2. Experimental setup............................... 7

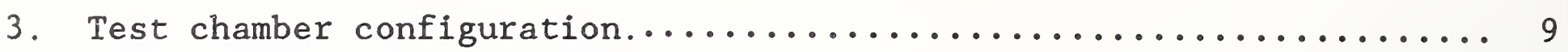

4. General variation of heat balance parameters as a function of

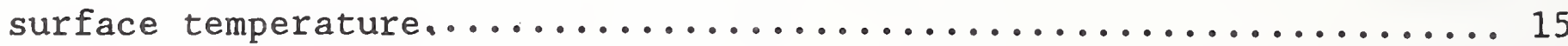

5. Transition from spontaneous ignition to combustion for a typical

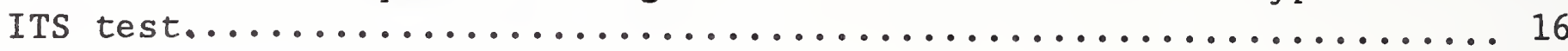

6. Abrupt ignition and combustion event during an LTS test........... 19

7. Typical surface and interior temperature waveforms for an LTS test... 21

8. Typical surface temperature waveform features from an LTS test..... 23

9. LTS test series ignition temperatures vs oxygen pressure........ 27

10. LTS test series combustion temperatures vs oxygen pressure....... 28

11. DTA thermograph of $N 07001$ alloy heated in oxygen.............. 30

12. Typical surface and interior temperature waveforms for an ITS test... 32

13. Development of ignition in $3.60 \mathrm{MPa}$ oxygen during an ITS test...... 34

14. Development of ignition in $14.41 \mathrm{MPa}$ oxygen during an ITS test..... 36

15. ITS test series spontaneous ignition temperatures vs oxygen

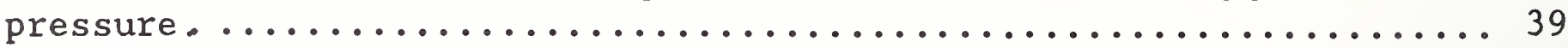

16. ITS test series enhanced oxidation temperatures vs oxygen pressure.. 40

17. ITS test series ignition temperatures vs oxygen pressure........4

18. ITS test series start-of-combustion temperature vs oxygen

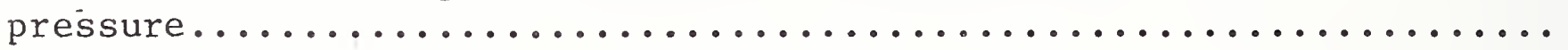




\section{List of Tables}

1. Materials selected for the determination of ignition and combustion

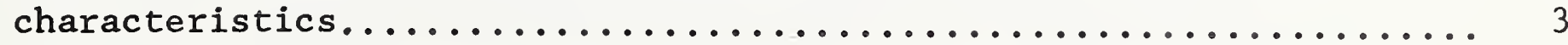

2. LTS test series ignition and combustion temperatures........... 26

3. ITS test series spontaneous ignition, enhanced oxidation, ignition,

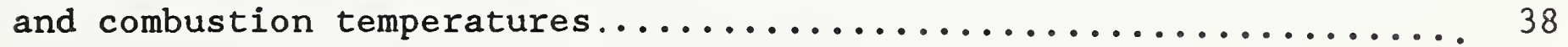

4. Linear least-squares curve fit coefficients for the ITS ignition parameter data shown in Figures 15, 16, and $17 \ldots \ldots \ldots \ldots \ldots \ldots$ 



\section{Ignition Characteristics of the Nickel-Based Alloy UNS N07001 in Pressurized Oxygen \\ James W. Bransford and Phillip A. Billiard}

The development of ignition and combustion in pressurized oxygen atmospheres was studied for the nickel-based alloy UNS N07001. Ignition of the alloy was achieved by heating the top surface of a cylindrical specimen with a continuous-wave $\mathrm{CO}_{2}$ laser. Two heating procedures were used. In the first, laser power was adjusted to maintain an approximately linear increase in surface temperature. In the second, laser power was periodically increased until autoheating (self-heating) was established. It was found that the alloy would autoheat to combustion from temperatures below the solidus temperature. In addition, the alloy had a tendency to develop combustion zones (hot spots) at high oxygen pressures when the incremental (step) heating test mode was used. Unique points on the temperature-time curves that describe certain events are defined and the temperatures at which these events occur are given for the oxygen pressure range of 1.72 to $13.8 \mathrm{MPa}$ (250 to $2000 \mathrm{psia}$ ).

Key words: alloys; combustion; ignition; ignition temperature; metal; nickel alloy; oxygen; oxygen compatibility 


\section{INTRODUCTION}

A number of serious accidents and catastrophic fires involving the ignition and subsequent combustion of metals have occurred in oxygen systems. As the operating pressure in oxygen systems has increased, the potential for disastrous ignition and combustion has also increased due, in part, to the increased reaction rate of materials with oxygen. To reduce the potential for ignition and combustion failure in oxygen systems, a knowledge of the ignition and combustion characteristics of metals is needed. Recognizing this need, the George C. Marshall Space Flight Center (MSFC) initiated a program at the National Institute of Standards and Technology (NIST) to study the ignition and combustion characteristics of selected alloys in pressurized oxygen. A list of the alloys being studied is given in table 1.

This report, the third in a series [1,2], details the results for the nickel-based alloy UNS N07001 (Waspaloy ${ }^{\mathrm{TM}}$ ). The studies involved heating the top surface of cylindrical specimens of the alloy by a continuous-wave (cw) $\mathrm{CO}_{2}$ laser in pressurized oxygen. The surface and interior temperatures were recorded as the specimens were heated. High speed cinematographic records of the ignition and combustion events were also obtained. From this information the spontaneous ignition (critical) temperature, enhanced oxidation temperature (our terminology), ignition temperature, combustion temperature, ignition and combustion morphology, and other information were obtained for the oxygen pressure range of 1.72 to $13.80 \mathrm{MPa}$ (250 to $2000 \mathrm{psia}$ ).

\footnotetext{
"Trade names are furnished to identify the material adequately. Such identification does not imply recommendation or endorsements by NIST, nor does it imply that the materials identified are necessarily the best available for the purpose.
} 


\begin{tabular}{|c|c|c|c|c|c|c|c|c|c|c|c|c|c|c|c|c|c|c|}
\hline 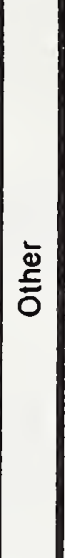 & 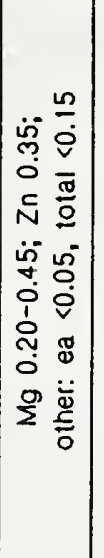 & 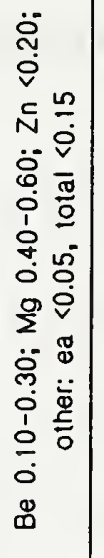 & $\begin{array}{l}\frac{\omega}{\dot{j}} \\
\dot{b} \\
\frac{\omega}{j} \\
\frac{0}{z}\end{array}$ & 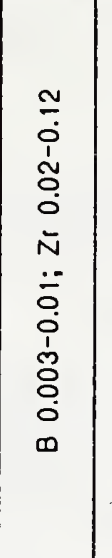 & 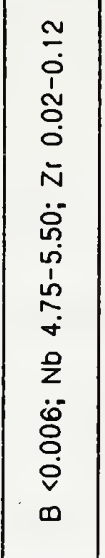 & 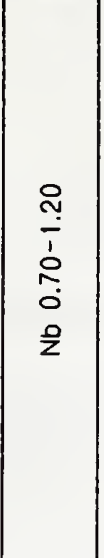 & $\begin{array}{l}\stackrel{\mathscr{m}}{\tilde{g}} \\
\stackrel{v}{v} \\
>\end{array}$ & & & & & & & & & $\begin{array}{l}0 \\
0 \\
0 \\
\vdots \\
0 \\
0 \\
> \\
>0 \\
0 \\
0 \\
0 \\
1 \\
\frac{1}{0} \\
0 \\
0 \\
\infty\end{array}$ & 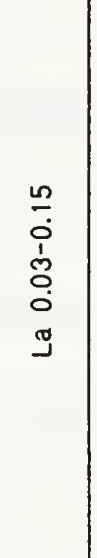 & $\begin{array}{l}\text { م } \\
\text { f } \\
\text { \& }\end{array}$ \\
\hline 3 & & & & & & & 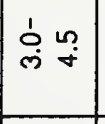 & & & & & & & & & & 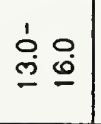 & \\
\hline$F$ & $\stackrel{\stackrel{\sim}{\sim}}{\stackrel{v}{v}}$ & 응 & $\begin{array}{l}\stackrel{q}{a} \\
\dot{0}\end{array}$ & 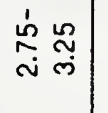 & 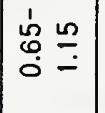 & $\stackrel{\stackrel{n}{n}}{\stackrel{\sim}{\sim} \sim} \underset{\sim}{\sim}$ & & & & & & & 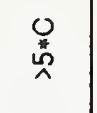 & & & O্ণ & & \\
\hline क & 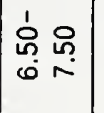 & 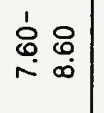 & 苔 & $\stackrel{\stackrel{n}{2}}{\stackrel{\rho}{v}}$ & $\stackrel{\mathscr{m}}{\tilde{g}}$ & 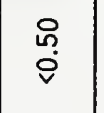 & $\stackrel{n}{0}$ & $\stackrel{\circ}{\bar{v}}$ & $\stackrel{\circ}{\dot{v}}$ & $\stackrel{\circ}{\dot{v}}$ & $\stackrel{\circ}{\bar{v}}$ & $\stackrel{\circ}{\bar{v}}$ & $\stackrel{\circ}{\bar{v}}$ & $\stackrel{\circ}{\bar{v}}$ & $\stackrel{\circ}{\bar{v}}$ & $\stackrel{\circ}{\dot{v}}$ & 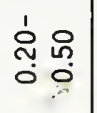 & \\
\hline$\infty$ & & & $\begin{array}{l}\frac{n}{0} \\
\stackrel{0}{Q}\end{array}$ & $\begin{array}{l}\stackrel{0}{0} \\
\stackrel{0}{0}\end{array}$ & $\begin{array}{l}\frac{n}{0} \\
\dot{0}\end{array}$ & $\begin{array}{l}0 \\
\stackrel{0}{0} \\
\stackrel{9}{\circ}\end{array}$ & $\begin{array}{l}\text { Oo. } \\
\stackrel{0}{\circ}\end{array}$ & $\begin{array}{l}\text { o. } \\
\stackrel{0}{\circ}\end{array}$ & 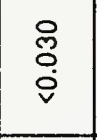 & 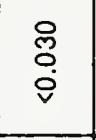 & $\begin{array}{l}\text { O్ } \\
\stackrel{0}{0} \\
\stackrel{0}{v}\end{array}$ & $\begin{array}{l}\text { o. } \\
\stackrel{0}{0} \\
\stackrel{8}{v}\end{array}$ & $\begin{array}{l}\stackrel{0}{0} \\
\stackrel{0}{0} \\
\dot{0}\end{array}$ & $\begin{array}{l}\stackrel{0}{0} \\
\stackrel{0}{0}\end{array}$ & $\begin{array}{l}\stackrel{0}{0} \\
\stackrel{0}{\circ}\end{array}$ & $\begin{array}{l}0 \\
\stackrel{0}{0} \\
\dot{0} \\
\dot{0}\end{array}$ & & \\
\hline a & & & $\begin{array}{l}\frac{n}{0} \\
\stackrel{0}{8}\end{array}$ & 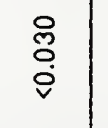 & $\begin{array}{l}\frac{n}{0} \\
\stackrel{0}{8}\end{array}$ & & ò & $\begin{array}{l}\stackrel{n}{0} \\
\stackrel{0}{0} \\
\stackrel{0}{0}\end{array}$ & $\begin{array}{l}\stackrel{n}{0} \\
\stackrel{0}{0} \\
\stackrel{0}{v}\end{array}$ & 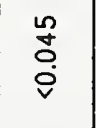 & 菅 & $\begin{array}{l}\stackrel{2}{0} \\
\stackrel{0}{0} \\
\dot{v}\end{array}$ & 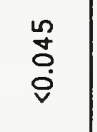 & $\begin{array}{l}\text { 号 } \\
\stackrel{0}{0} \\
\dot{8}\end{array}$ & 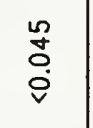 & $\begin{array}{l}\dot{0} \\
\stackrel{0}{0} \\
\dot{8}\end{array}$ & & \\
\hline $\bar{z}$ & & 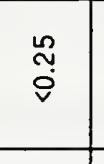 & $\dot{0}$ & 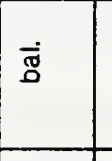 & 官品 & $\stackrel{\circ}{\stackrel{0}{n}}$ & $\overrightarrow{\mathrm{g}}$ & $\stackrel{1}{\dot{0}} \underset{\infty}{\infty}$ & $\begin{array}{l}\dot{1} \\
\infty\end{array}$ & $\begin{array}{l}1 \\
\infty \\
\infty \\
\infty\end{array}$ & 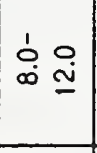 & 兑足 & $\begin{array}{ll}\dot{1} & \circ \\
\stackrel{\circ}{ }\end{array}$ & $\dot{\circ} \stackrel{\circ}{\circ}$ & & 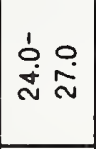 & \begin{tabular}{ll}
$\dot{1}$ & 0 \\
$\stackrel{\sim}{\sim}$ & \multicolumn{1}{|c|}{}
\end{tabular} & $\dot{\square}$ \\
\hline$\frac{0}{2}$ & & & $\begin{array}{l}\dot{\infty} \\
\infty\end{array}$ & 占 & 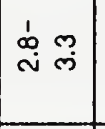 & & 宊 & & & & & $\stackrel{\dot{\sim}}{\dot{i}}$ & & & $\stackrel{\stackrel{n}{\circ}}{\stackrel{9}{v}}$ & بْ & & \\
\hline$\frac{c}{\Sigma}$ & $\stackrel{\mathscr{e}}{\stackrel{\rho}{v}}$ & $\stackrel{\text { ণิ }}{\stackrel{\nabla}{\vee}}$ & 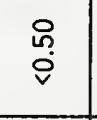 & $\stackrel{\circ}{\bar{v}}$ & $\stackrel{\mathscr{m}}{\stackrel{\rho}{v}}$ & $\stackrel{\circ}{\dot{V}}$ & $\stackrel{\circ}{\bar{v}}$ & $\stackrel{\text { ì }}{\mathrm{v}}$ & $\stackrel{\circ}{i}$ & $\stackrel{\text { ì }}{\text { Var }}$ & $\stackrel{\text { ํํ }}{ }$ & $\stackrel{\circ}{ن}$ & 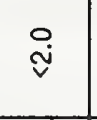 & $\stackrel{\text { ì }}{ }$ & $\stackrel{\circ}{\bar{v}}$ & 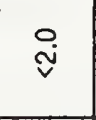 & $\stackrel{\stackrel{\sim}{\oplus}}{\bar{v}}$ & \\
\hline$\stackrel{\leftrightarrow}{\longleftarrow}$ & $\stackrel{\circ}{\circ}$ & o̊ & $\stackrel{\circ}{\dot{\varphi}}$ & 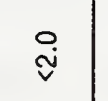 & $\overrightarrow{\mathrm{g}}$ & $\begin{array}{ll}1 & 0 \\
i n & \circ\end{array}$ & ơ & 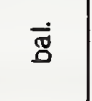 & $\overline{\mathrm{g}}$ & बं & $\dot{\Phi}$ & $\dot{\Phi}$ & $\overrightarrow{\mathrm{\Phi}}$ & $\dot{\mathbf{g}}$ & $\overrightarrow{\mathrm{s}}$ & ळं & ֶे & \\
\hline ठౌ & $\stackrel{\sim}{\stackrel{\sim}{v}}$ & ঙ̊ণ & & 品 & 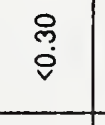 & 宫 & & & & & & & & & & & & \\
\hline$\overline{0}$ & & ָัָ & 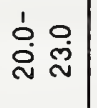 & 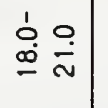 & 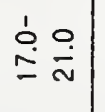 & 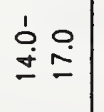 & 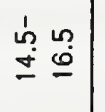 & 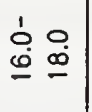 & $\begin{array}{ll}\stackrel{1}{a} & 0 \\
& \stackrel{g}{0}\end{array}$ & 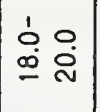 & $\begin{array}{ll}1 & 0 \\
\infty & \stackrel{0}{\circ}\end{array}$ & $\begin{array}{ll}0 & 0 \\
0 & 0 \\
0 & \infty\end{array}$ & $\stackrel{\circ}{\stackrel{9}{=} \stackrel{\circ}{\Xi}}$ & 茰 & 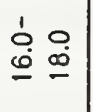 & 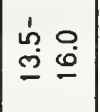 & $\begin{array}{l}1 \\
\text { ì } \\
\text { ì }\end{array}$ & \\
\hline 8 & & & & 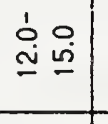 & $\stackrel{\circ}{\dot{v}}$ & & $\stackrel{\sim}{\sim}$ & & & & & & & & & & $\overrightarrow{\mathrm{g}}$ & \\
\hline 0 & & & $\frac{9}{\dot{0}}$ & 今心o & $\stackrel{\infty}{\stackrel{0}{0}}$ & $\begin{array}{l}\infty \\
\stackrel{0}{0}\end{array}$ & $\begin{array}{l}\tilde{0} \\
\stackrel{0}{0}\end{array}$ & $\frac{n}{\dot{Q}}$ & $\frac{n}{9}$ & $\begin{array}{l}\infty \\
\stackrel{0}{0} \\
\stackrel{0}{\circ}\end{array}$ & $\stackrel{0}{0}$ & $\begin{array}{l}\infty \\
\stackrel{0}{0} \\
\stackrel{v}{v}\end{array}$ & $\begin{array}{l}\infty \\
\stackrel{0}{0} \\
\stackrel{0}{v}\end{array}$ & $\begin{array}{l}\text { : } \\
\stackrel{0}{0}\end{array}$ & 峚 શ̣ & $\begin{array}{l}0 \\
\stackrel{0}{0} \\
\stackrel{0}{0}\end{array}$ & 岁 & \\
\hline $\bar{\alpha}$ & $\overrightarrow{\mathrm{g}}$ & $\overrightarrow{\mathrm{I}}$ & $\stackrel{9}{\circ}$ & 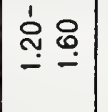 & 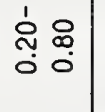 & ơ & & & & & & & & & & 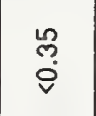 & & \\
\hline 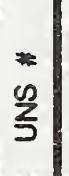 & 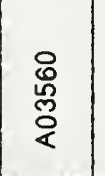 & 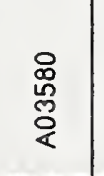 & $\begin{array}{l}\stackrel{0}{0} \\
\stackrel{0}{0} \\
\stackrel{0}{z}\end{array}$ & $\begin{array}{l}\bar{o} \\
\text { ò } \\
\text { ò }\end{array}$ & $\frac{\infty}{\frac{\infty}{\hat{0}}}$ & 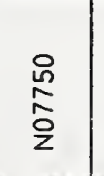 & 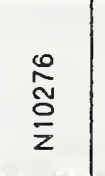 & 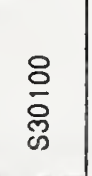 & $\begin{array}{l}\text { ○े } \\
\text { ळ్ల }\end{array}$ & 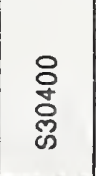 & $\begin{array}{l}\text { o } \\
\text { ờ } \\
\text { ळ్ }\end{array}$ & 各 & $\frac{8}{\check{\tilde{ల}}}$ & $\begin{array}{l}8 \\
\text { 岕 } \\
\text { ळ. }\end{array}$ & 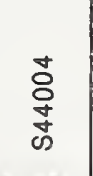 & $\begin{array}{l}0 \\
\stackrel{0}{0} \\
\stackrel{0}{0} \\
\infty\end{array}$ & $\begin{array}{l}\infty \\
\stackrel{\infty}{\infty} \\
\frac{\infty}{\Sigma}\end{array}$ & 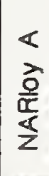 \\
\hline
\end{tabular}




\section{EXPERIMENTAL PROCEDURE}

Cylindrical test specimens (fig. 1) were machined from commercially available UNS N07001 alloy rod that had a hardness of Rockwell C 38 . The rod had a chemical composition of $1.368 \mathrm{Al}, 0.005 \% \mathrm{~B}, 0.048 \% \mathrm{C}, 13.968$ Co, $19.40 \%$ $\mathrm{Cr}, 0.038 \mathrm{Cu}, 1.248 \mathrm{Fe}, 0.028 \mathrm{Mn}, 4.128 \mathrm{Mo}, 0.0068 \mathrm{P}, 0.0028 \mathrm{~S}, 0.068 \mathrm{Si}$, 3.10\% Ti, 0.0668 $\mathrm{Zr}$ with the balance Ni. Specimen dimensions were $6.35 \mathrm{~mm}$ (0.25 in) in diameter by $6.35 \mathrm{~mm}(0.25 \mathrm{in})$ in height for the linear temperature increase tests and $8.00 \mathrm{~mm}(0.31 \mathrm{in})$ in diameter by $6.35 \mathrm{~mm}(0.25$ in) height for the incremental temperature increase tests. A thermocouple hole was drilled axially to within $0.25 \pm 0.05 \mathrm{~mm}(0.010 \pm 0.002$ in) of the top surface. The top surface of the specimen was maintained in the machined finish, spiral groove approximately $0.08 \mathrm{~mm}(0.003 \mathrm{in})$ in depth, to improve the absorption of the laser beam at the beginning of an experiment and also to give a diffuse laser beam reflection which would minimize potential heat damage to the chamber liner or other chamber components.

The experiments were carried out in commercially pure oxygen. Chamber pressure was varied from 1.72 to $13.8 \mathrm{MPa}$ (250 to $2000 \mathrm{psia}$ ) in $1.72 \mathrm{MPa}$ (250 psia) steps. Oxygen pressures lower than $1.72 \mathrm{MPa}$ could not be used because gaseous oxides produced during the high temperature combustion phase of the experiments produced splatter which destroyed the laser beam window after several experiments. The chamber pressure was allowed to increase, due to the heating of the oxygen, during the experiments and was recorded at the beginning of specimen combustion. The chamber pressure increase at combustion rarely exceeded the initial chamber pressure by 10 percent.

To assemble an experiment, a specimen was mounted in a machined graphite block but was insulated from the block by approximately $3 \mathrm{~mm}$ of aluminum oxide 

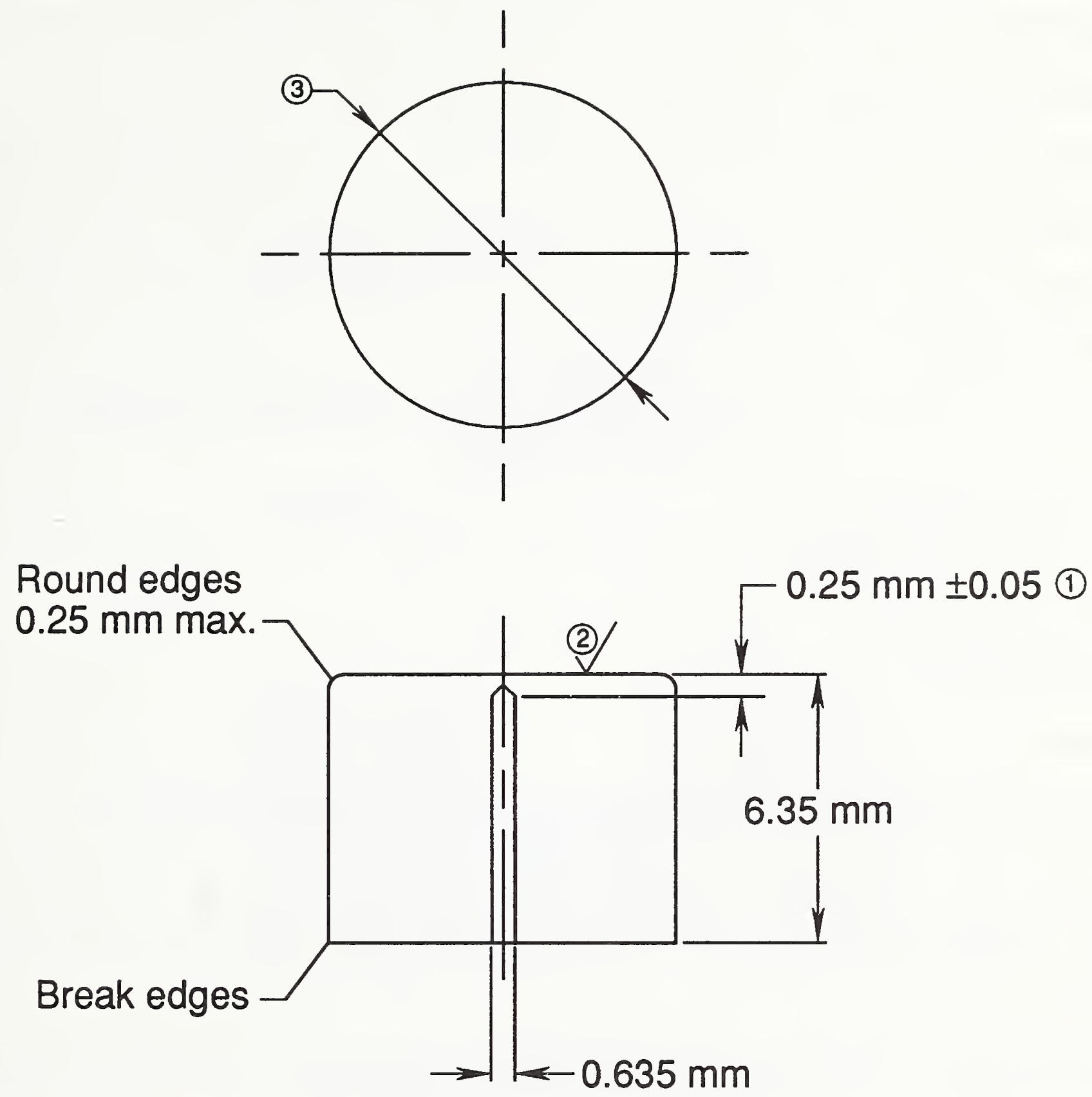

NOTES:

1. Apex to top surface center.

2. Surface finish as specified

3. $6.35 \mathrm{~mm}$ or $8.00 \mathrm{~mm}$ dia. as req'd.

Figure 1. Test specimen configuration. 
powder packed to a density of approximately $1 \mathrm{gm} / \mathrm{cc}$. This assembly was placed upon a ceramic foam pad which was then placed on a pedestal (fig. 2). The heat loss from this configuration was significantly less than would normally be experienced by metallic materials in most oxygen systems.

The top surface of the specimen was heated by a $\mathrm{cw} \mathrm{CO}_{2}$ laser beam. The laser provided a controllable noncontaminating heat source. The laser was detuned from the pure $\mathrm{TEM}_{00}$ mode so as to contain higher order modes. This procedure distributed the laser power more evenly across the laser beam and thus heated the specimen more uniformly. The laser beam was focused to cover approximately 80 percent of the top surface of the specimen. This allowed the beam to remain predominantly on the specimen surface despite random refraction of the beam by convection currents of heated gas rising from the heated specimen surface.

Two heating procedures were used in this study. The first procedure established and maintained an approximately linear increase in specimen surface temperature and was called the Linear Temperature Scan (ITS) heating procedure. Surface heating rates of $100 \mathrm{~K} / \mathrm{min}$ were most often used, however, rates of up to $250 \mathrm{~K} / \mathrm{min}$ were used occasionally. The LTS heating procedure was used primarily to determine whether rapidly developing exothermic events, including ignition, were present, but the tendency of a material to autoheat (self-heat), which is usually a much slower exothermic process, was also detectable.

The second heating procedure incrementally increased the laser beam power. The surface was allowed to reach short-term equilibrium before another power increment was applied. At some power level during the procedure, the surface temperature would not reach equilibrium and the material would 


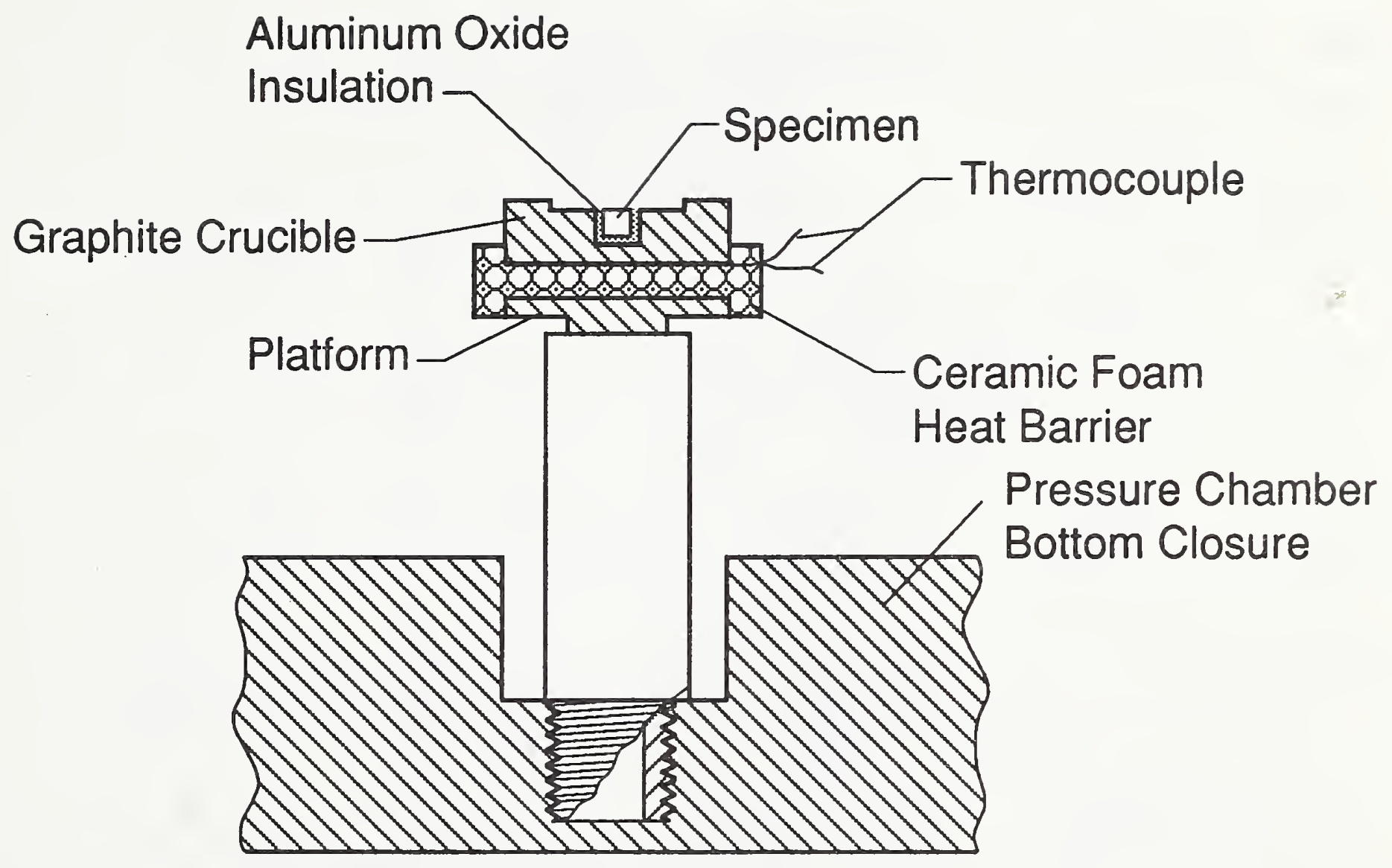

Figure 2. Experimental setup. 
autoheat to combustion. This procedure was called the Incremental Temperature Scan (ITS) heating procedure.

The surface and interior temperatures of the specimen were the principal dependent variables measured in this study. The surface temperature was measured using two-color ratio pyrometry. Two pyrometers were ultimately used. One pyrometer covered the temperature range of 973 to $1773 \mathrm{~K}$ (1292 to $2732^{\circ} \mathrm{F}$ ) and had an output range which gave a temperature sensitivity of $8 \mathrm{~K} / \mathrm{mV}$ $\left(14^{\circ} \mathrm{F} / \mathrm{mV}\right)$. The second pyrometer covered the temperature range of 1173 to 2673 K (1652 to $4352^{\circ} \mathrm{F}$ ) and had an output range which gave a temperature sensitivity of $15 \mathrm{~K} / \mathrm{mV}$. These signals were recorded by a 4-channel digital oscilloscope which used 15 bit analog to digital (A/D) converters. The A/D converters have a maximum voltage resolution of $6.25 \mu \mathrm{V}$. Thus, maximum temperature resolution was $0.05 \mathrm{~K}\left(0.09^{\circ} \mathrm{F}\right)$ for the 973 to $1773 \mathrm{~K}$ range pyrometer and $0.09 \mathrm{~K}\left(0.16^{\circ} \mathrm{F}\right)$ for the 1173 to $2673 \mathrm{~K}$ range pyrometer.

The pyrometers viewed the specimen through the pressure chamber observation windows which were oriented at $45^{\circ}$ from the vertical (fig. 3 ). The specimen surface observed within the circular measurement field of view of the pyrometers was elliptical and covered top surface dimensions that varied from approximately 5 to $7 \mathrm{~mm}(0.2$ to $0.3 \mathrm{in})$. The pyrometers did not measure the maximum surface temperature, but responded to the overall temperature of the viewed area. The temperature was not an average but was biased toward the highest temperature within the measurement area due to the non-linear dependence of radiated power on temperature.

The interior temperature was measured with a platinum versus platinum108 rhodium (Type S) thermocouple. The thermocouple was insulated except for the bead, which was in contact with the specimen at the top of the 


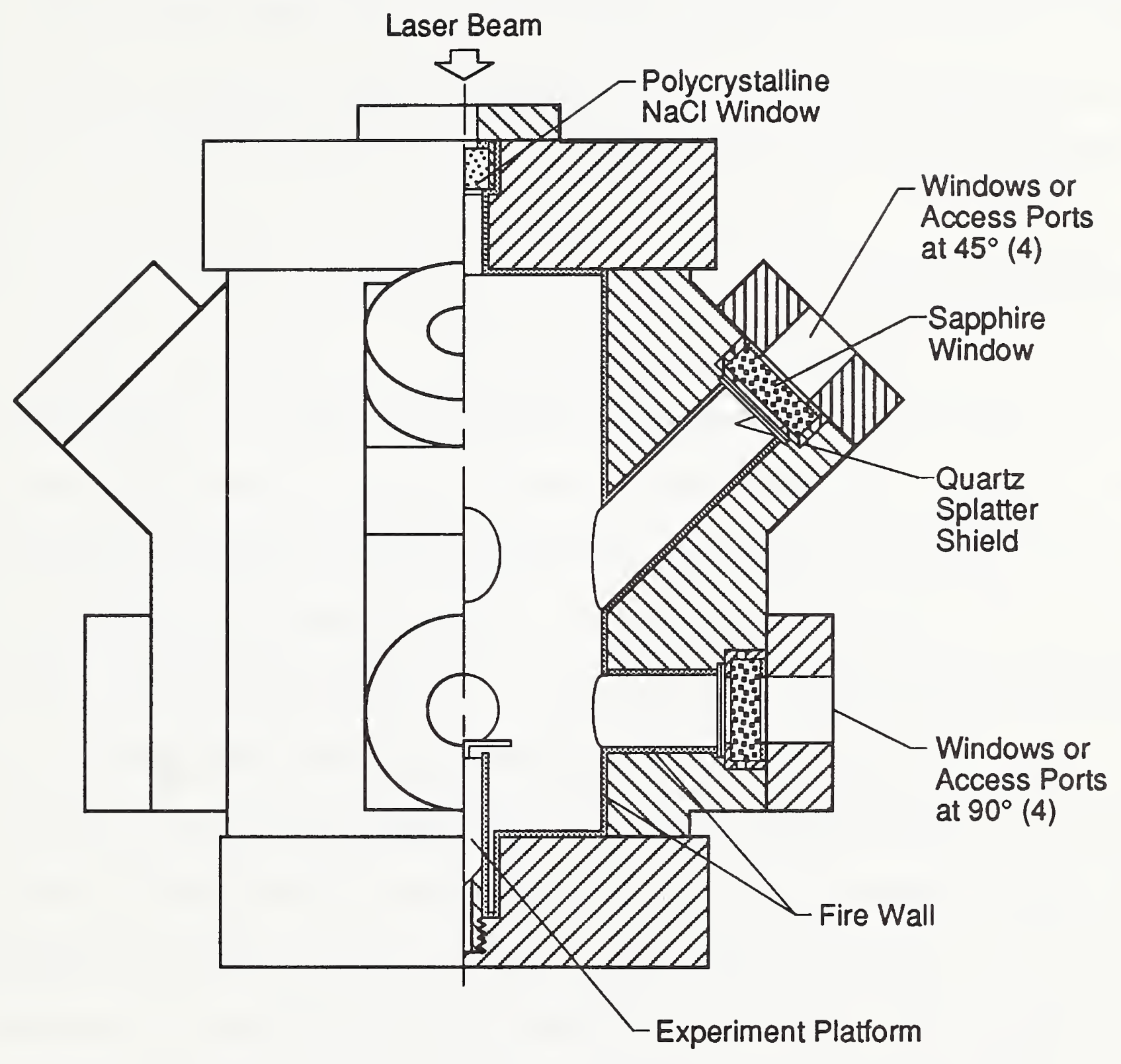

Figure 3. Test chamber configuration. 
thermocouple well. The output of the thermocouple was referenced to a $273 \mathrm{~K}$ cold junction and then digitized directly at the maximum sensitivity of the digitizers, $6.25 \mu \mathrm{V}$. This gave a temperature sensitivity of approximately 0.6 $\mathrm{K}\left(1^{\circ} \mathrm{F}\right)$ over the temperature range of interest, 973 to $1773 \mathrm{~K}$.

Special tests in which the thermocouple was spot-welded to the top surface were also run. These tests were used to obtain estimates of the temperatures of the alloy/oxide interface.

\section{METAL IGNITION PROCESS}

A detalled mathematical description of the metal ignition process requires a quantitative knowledge of a significant number of variables. However, a general nonmathematical understanding may be gained by considering a generalized temperature-dependent heat balance for a surface undergoing oxidation and external heating (fig. 4). The heat balance is composed of the following parameters:

1. $\dot{Q}_{(10 s s)}$ - the rate at which the oxidizing surface loses heat by conduction, convection, and radiation;

2. $\dot{Q}_{(\theta x t)}$ - the rate at which external sources transfer heat to the oxidizing surface by conduction, convection, and radiation.

3. $\dot{Q}_{(\mathrm{chem})}$ - the rate at which oxidation of the alloy generates heat at the oxidizing surface;

4. $\dot{Q}_{(\text {in })}$ - the sum of $\dot{Q}_{(\text {ext })}$ and $\dot{Q}_{(\text {chem })}$.

To further simplify the description, $\dot{Q}_{(\text {ext) }}$ will be a constant, but different, value for each of the illustrations in figure 4. Both $\dot{Q}_{(l o s s)}$ and $\dot{Q}_{(\text {chem })}$ are dependent functions of the surface temperature as well as other variables which will remain constant for this discussion. 
The initial application of $\dot{Q}_{(e x t)}$, which is less than that required to initiate ignition, will increase the magnitude of $\dot{Q}_{(i n)}$ to some value greater than $\dot{Q}_{(10 s)}$. The surface temperature, $T_{s}$, will increase and reach an equilibrium temperature, $T_{\text {eq }}$, where $\dot{Q}_{(\text {loss })}$ will equal $\dot{Q}_{(\text {in })}$ (fig. $\left.4 \mathrm{a}\right)$. Since $\dot{Q}_{(e x t)}$ is less than that required for ignition, the slope of the $\dot{Q}_{(i n)}$ curve will be less than the slope of the $\dot{Q}_{(\text {loss })}$ curve at $T_{\text {eq }}$. The oxidizing surface temperature cannot increase beyond $\mathrm{T}_{\text {eq }}$ irregardless of the oxidation mode that is occurring, protective or unprotective, because an increase in heating rate will be less than the increase in cooling rate at temperatures greater than $\mathrm{T}_{\text {eq }}$. Therefore, $\mathrm{T}_{\text {eq }}$ will be a stable surface temperature in the sense that it cannot increase. However, the long-term stability of $\mathrm{T}_{\text {eq }}$ over time will depend upon whether the surface is undergoing protective (time-dependent) or nonprotective (time-independent) oxidation. If protective oxidation is occurring, $\dot{Q}_{(c h e m)}$ will decrease with time as the oxidation rate decreases with increasing oxide layer thickness. Since $\dot{Q}_{(\text {chem })}$ is decreasing with time, so is $\dot{Q}_{(\text {in })}$; so will the oxidizing surface temperature decrease with time. If nonprotective oxidation is occurring, $\dot{Q}_{(\mathrm{chem})}$ will remain constant, assuming all other variables remain constant, and the oxidizing surface temperature will remain constant.

As $\dot{Q}_{(e x t)}$ is systematically increased, an equilibrium surface temperature will ultimately be reached at which the slope of the $\dot{Q}_{(\text {in })}$ curve equals the slope of the $\dot{Q}_{\text {(loss) }}$ curve (fig. 4b). This equilibrium temperature is defined as the spontaneous ignition (or critical) temperature, $T_{s p}[3]$. Since $\dot{Q}_{\text {(chem) }}$ and $\dot{Q}_{(10 s s)}$ both increase with increasing temperature, the slopes of the $\dot{Q}_{(\mathrm{In})}$ and $\dot{Q}_{(\text {Ioss })}$ curves may be approximately equal over a fairly wide temperature range, relative to most run-away oxidation reactions. We have previously 
described this range as a quasi-stable temperature region [4]. The behavior of an alloy within this region is of interest. Small shifts in the value of various factors which change the heating or cooling rate will cause the oxidizing surface to cool or to autoheat (self-heat). At $\mathrm{T}_{\mathrm{sp}}$, the relationship between the $\dot{Q}_{(\text {in })}$ and $\dot{Q}_{(10 s s)}$ curves may be used to define several unique events (or ignition parameters). These are:

1. Spontaneous ignition temperature, $\mathrm{T}_{\mathrm{sp}}$ - the temperature at which $\mathrm{dQ}_{(1 n)} / \mathrm{dT}_{\mathrm{S}}=\mathrm{dQ} \dot{\mathrm{Q}}_{(10 \mathrm{~s} s)} / \mathrm{dT}_{\mathrm{S}}$

2. Ignition temperature, $T_{i g n}$ - the temperature at which $\left[\dot{Q}_{(\text {in })}-\dot{Q}_{(\text {loss })}\right]$ is maximum .

These parameters are shown in figure $4 \mathrm{~b}$. It should be clear that $\mathrm{T}_{\mathrm{sp}}$ and $\mathrm{T}_{\text {ign }}$ are not fundamental material properties, but are functions of the relationship between the $\dot{Q}_{(1 n)}$ and $\dot{Q}_{(10 s)}$ curves. Therefore, the values of $T_{s p}$ and $T_{i g n}$ will change as the shape of the heat balance parameters curves, $\dot{Q}_{(\text {in) }}$ and $\dot{Q}_{(\text {loss })}$, changes .

If autoheating is sufficiently slow, as may be the case with bulk quantities of material because the bulk mass acts as a heat-sink, an equilibrium surface temperature greater than $\mathrm{T}_{\mathrm{sp}}$ may be established by decreasing $\mathrm{Q}_{(\mathrm{ext})}$ once the surface temperature has exceeded $\mathrm{T}_{\mathrm{sp}}$. However, such an equilibrium surface temperature must be considered unstable because the slope of the $\dot{Q}_{(i n)}$ curve is greater than the slope of the $\dot{Q}_{(\text {loss })}$ curve and the surface will tend to autoheat.

It is useful to consider the effect of physical state on the ignition parameters that have been introduced. In general, the oxidation rate of the solid alloy is less than that of the liquid alloy. Therefore, if $\mathrm{T}_{\mathrm{sp}}$ occurs while the alloy is solid, a phase-dependent ignition temperature, $\mathrm{T}_{\text {ign }}$, may be 
defined. However, defining a liquid phase ignition temperature would be difficult because of the effects of fluid flow. As a liquid oxidizing fluid begins to flow, the rate of material oxidation will be significantly increased by the exposure of unoxidized material. This, in turn, significantly

increases the rate of heat generation and thus the surface temperature for the flow interval. The net result of fluid flow is to disrupt the smoothness of the nonflow $\dot{Q}_{(\mathrm{chem})}$ curve. This makes it difficult to determine flow induced oxidation effects from quiescent oxidation effects. For this reason, liquid phase ignition parameters and their temperatures were not determined for the ITS heating procedure (with the exception of the temperature at the beginning of the flow interval, which is defined as combustion, $T_{c m b}$ ); only solid phase ignition parameters were determined.

If $\dot{Q}_{(e x t)}$ is sufficiently large, the $\dot{Q}_{(1 n)}$ curve will not intersect the $\dot{Q}_{(10 s s)}$ curve (fig. 4c). In this case, $T_{s p}$ is not obtainable from the experiment, however, $T_{\text {ign }}$ is. $T_{\text {ign }}$ does not differ in this case from the case shown in figure $4 \mathrm{~b}$. This is due to the definition of $T_{\text {ign }}$ as being the temperature at the maximum deviation between the $\dot{Q}_{(i n)}$ curve and the $\dot{Q}_{(10 s s)}$ curve. This means that our experiments which use the ITS heating procedure can be thermally overdriven without seriously affecting the value of $T_{\text {ign }}$. However, the excess external heat input cannot be orders of magnitude more.

The exact shape and magnitude of the $\dot{Q}_{(\text {in })}$ and $\dot{Q}_{(\text {loss })}$ curves are not known. Therefore, the determination of the ignition parameters must be based upon other measurable quantities. In our studies the surface and interior temperatures were used. However, the surface temperature does have several problems associated with its use. 
As the surface temperature increases, the absorptivity (which is equal to the emissivity) of the oxide layer changes, apparently increasing at the $\mathrm{CO}_{2}$ laser wavelength more than at other shorter wave lengths. In our test, in which a laser was used as the external heat source, this changing absorptivity appeared to result in an increased heating rate over time at a constant laser power input without a corresponding increase in the radiative cooling rate. If a positive heating rate accrues, it will appear to be autoheating on the temperature-time waveform and indicate a false spontaneous ignition temperature.

To determine the spontaneous ignition temperature, the apparent changing absorptivity effect on specimen heating had to be separated from the oxidation contribution. This was accomplished by running a number of tests using heavily preoxidized specimens. These tests, when compared to the standard test, showed that the contribution to the heating rate from the apparent changing absorptivity, for constant laser power, was linear or nearly linear. Since the oxidation rate of metals and alloys is nonlinear with temperature, spontaneous ignition was assumed to have occurred at the temperature where the temperature-time waveform became nonlinear under constant laser power input (fig. 5). For N07001, the interior temperature-time waveform must be used for analysis because the pyrometer measurement was adversely affected by the apparent nonlinear emissivity of the surface oxide. If no measurement problem existed, the surface and interior temperature waveforms would be parallel. This was not the case for N07001, as is seen in figure 5.

We have defined an additional ignition parameter that may be unique to our experiments. This parameter defines the beginning of a region on the ITS temperature-time waveform where an abrupt change in curvature occurs after $\mathrm{T}_{\mathrm{sp}}$ 

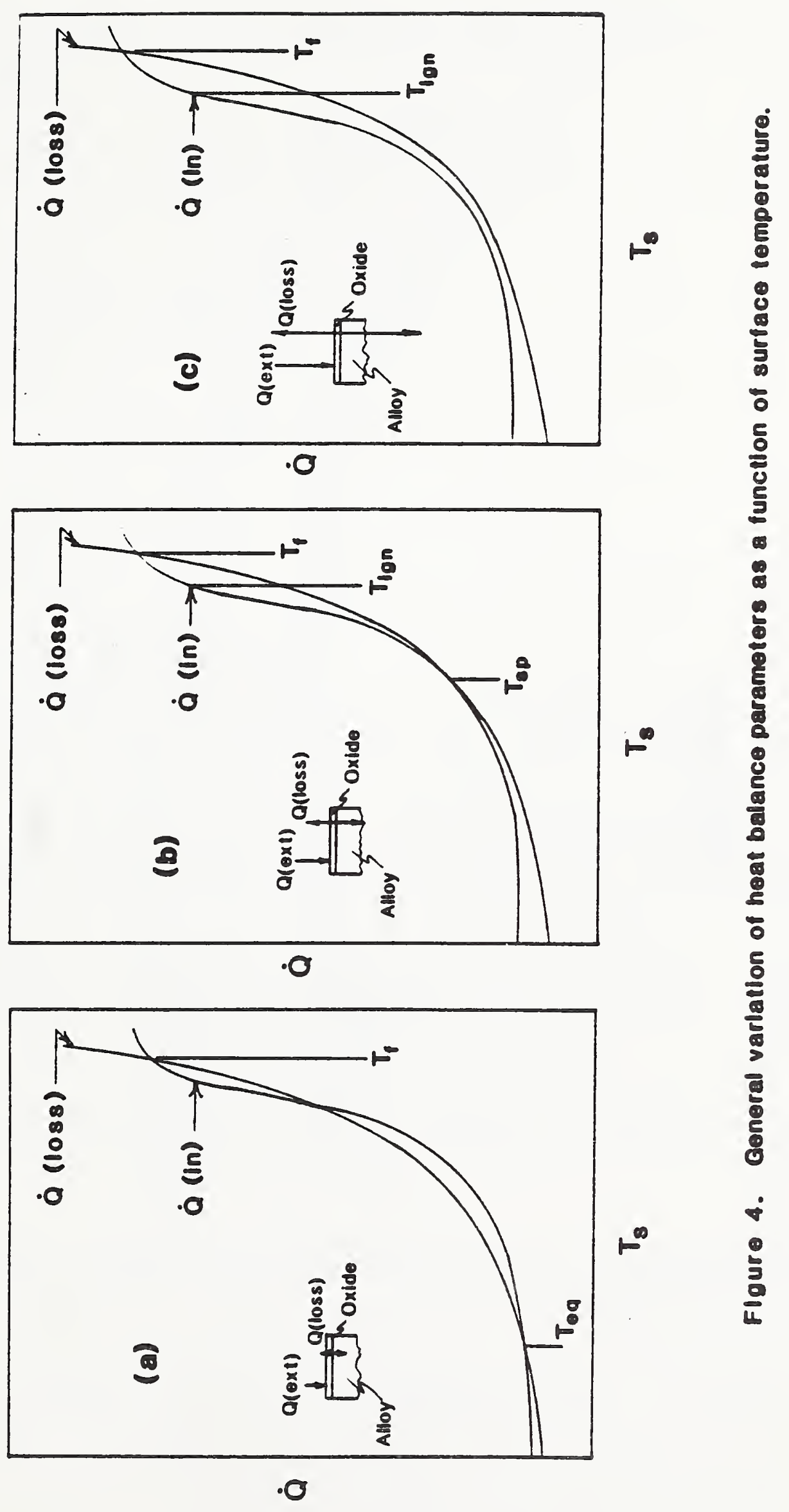


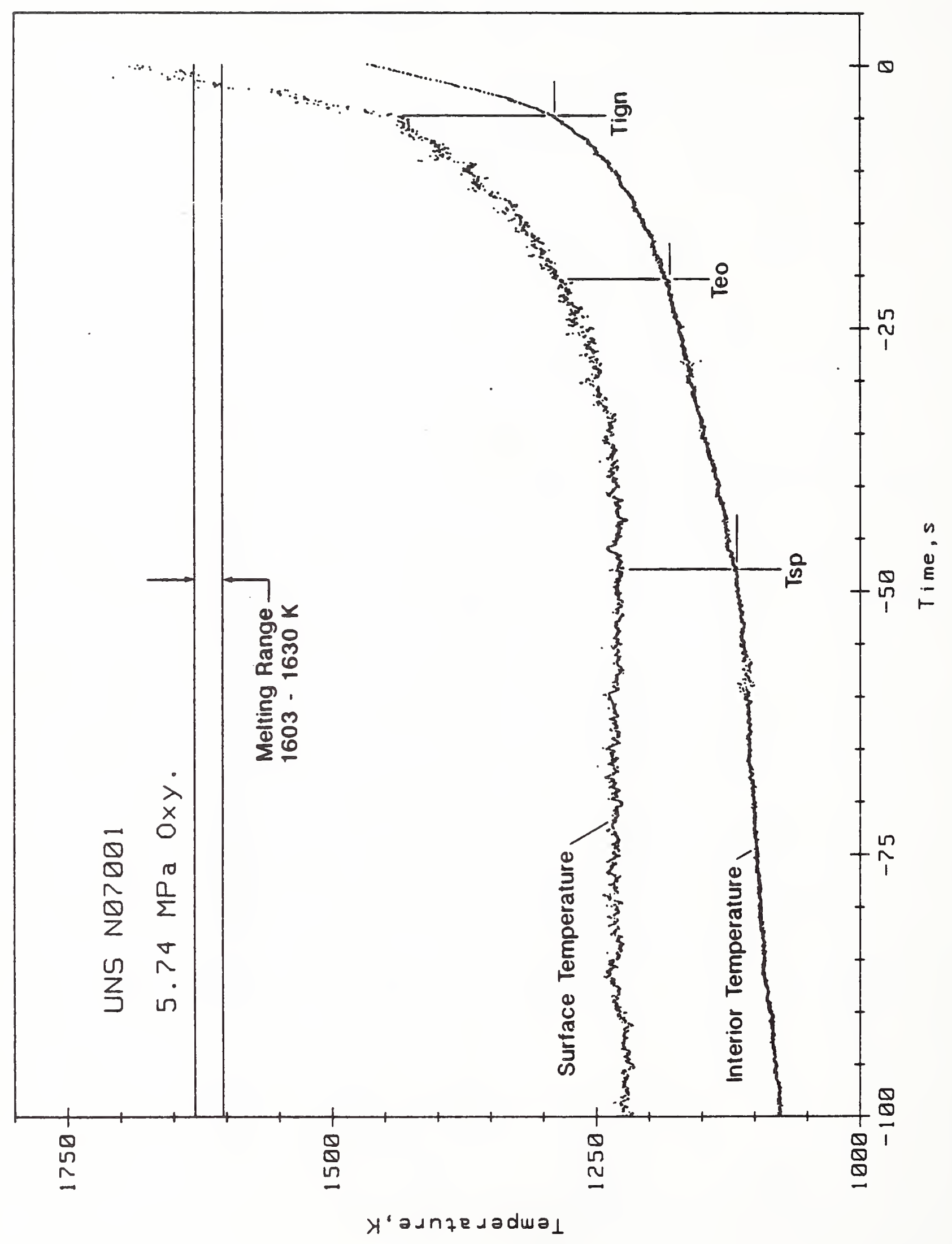

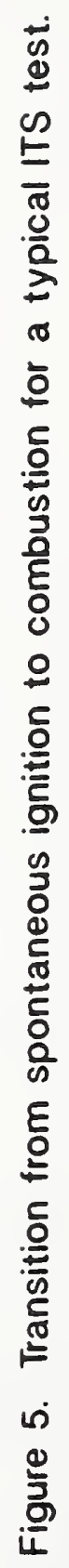


and prior to $T_{\text {ign }}$ (fig. 5). The region generally contains several abrupt changes in temperature which, for many alloys, usually appear in conjunction with clearly observable endothermic features in the surface temperature waveform. For N07001, these endothermic features are not clearly observable; however, the abrupt changes in curvature usually were discernible. Using all ITS tests, sufficient evidence was available to indicate that endothermic events were occurring in conjunction with the abrupt changes in curvature. Thus, we have postulated, as we have with other alloys, that the source of these events increased or enhanced the oxidation rate of the alloy. The temperature at the beginning of this region we have called the enhanced oxidation temperature, $\mathrm{T}_{e o}$, and appears to be associated with the beginning of the rapid buildup of the oxide layer. We speculate, but have not demonstrated, that $\mathrm{T}_{\text {eo }}$ lies in a temperature region where the oxidation mechanism is changing from protective to nonprotective oxidation. This mechanism change has not been incorporated into the $\dot{Q}_{(\text {chem })}$ and $\dot{Q}_{(\text {in) }}$ curves of figure 4 nor discussed extensively. The oxidation mechanism change, where it exists, probably causes a rapid change in the $\dot{Q}_{(\text {chem })}$ curve slope.

The ignition temperature was the most straightforward parameter to determine, because the definition of this event requires the existence of a maximum heating rate of the specimen. Ignition was assumed to have developed as the maximum rate of change in the surface, or interior, temperature occurred (fig. 5).

A number of factors can influence the shape and magnitude of the $\dot{Q}_{(\text {in) }}$ and $\dot{Q}_{(10 s s)}$ curves. The $\dot{Q}_{(10 s)}$ curve alone can be easily modified by improving or impeding heat transfer from the oxidizing interface. The $\dot{Q}_{(i n)}$ curve may be modified by the existence of fluid oxide phases (which may exist above certain 
temperatures) at the oxidizing interface. These phases may increase the oxidation rate of many alloys $[4,5]$. The $\dot{Q}_{(\text {chem })}$ component of the $\dot{Q}_{(\text {in) }}$ curve is also modified when the oxidation rate changes from protective (timedependent) to nonprotective (time-independent). When either the $\dot{Q}_{(i n)}$ or $\dot{Q}_{\text {(1oss) }}$ curve is changed, the values of the ignition events will also change. In general, the lower the heat transfer rate from the oxidizing surface, the lower the temperatures at which $T_{s p}, T_{80}$, and $T_{1 g n}$ will occur; conversely, the greater the heat transfer rate, the higher the temperature at which $\mathrm{T}_{\mathbf{s p}}, \mathrm{T}_{\boldsymbol{\theta}}$, and $T_{1 g n}$ will occur. The temperatures at which ignition parameters occur are not fundamental material properties; instead, their values are controlled by a number of material properties and external inputs.

Under certain experimental conditions and/or at elevated oxygen pressures, combustion may develop abruptly before the above defined $\mathrm{T}_{\text {ign }}$ occurs, as shown in figure 6. These abrupt combustions may be due to cracking or spalling of the surface oxides which expose minimally oxidized material. If the surface oxides are impeding the transfer of oxygen to the oxidizing surface the resulting rapid increase in oxidation rate may produce sufficient heat, in a region of restricted heat loss, to melt a small volume of the alloy. A feedback effect may result which produces either immediate combustion or a small combustion region, hot-spot, which may expand rapidly. This type of event has also been called ignition, thus creating an unavoidable dual definition for $T_{\text {ign }}$.

The terms "combustion" or "combustion region" are used in this report. This terminology usually implies evaporation and vapor phase oxidation of the fuel material. For the N07001 alloy, vapor phase combustion does not occur. For this alloy, and most others listed in table 1 with the exception of the 


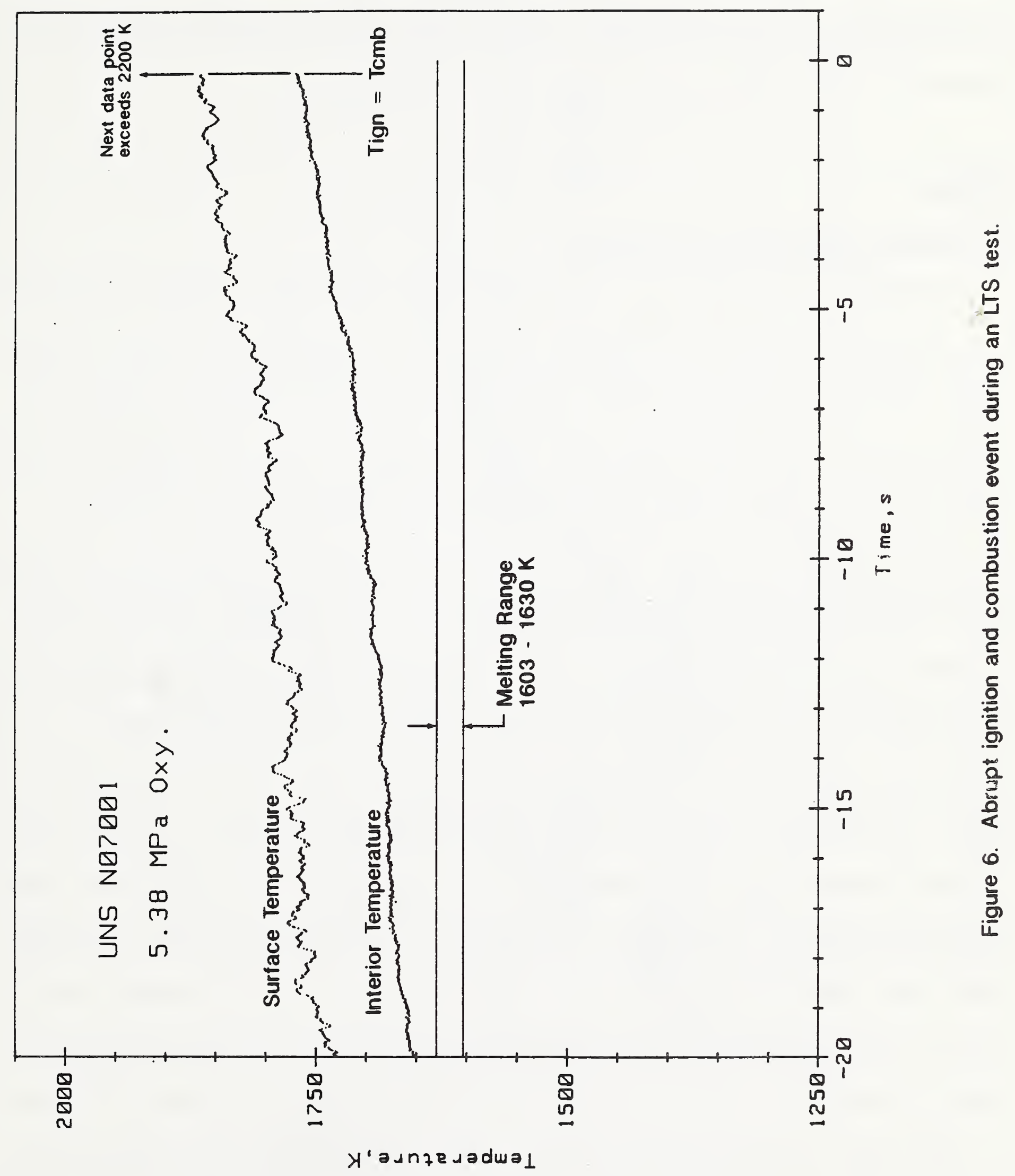


aluminum alloys, combustion is the fluid flow enhanced oxidation of the liquid alloy. Flow enhanced fluid oxidation generates very high temperatures, $2500 \mathrm{~K}$ and higher, and develops in milliseconds as the specimen melts and collapses. The beginning of the development of these high temperatures is called the combustion temperature, $T_{\mathrm{cmb}}$, and is shown in figure 6 .

\section{RESULTS}

\section{Linear Temperature Scan Tests}

Analysis of a number of combustion events in oxygen systems constructed of aluminum, iron, or nickel based alloys, or a combination of those alloys, indicated that combustion events appeared to develop rapidly, possibly in milliseconds. The environmental history leading to these combustion events were usually unknown. Thus, the immediate thermal history of the oxygen system materials involved in the combustion event and the presence or absence of an oxidation reaction induction period was also unknown. We therefore decided that the initial course of investigation should assume an abrupt solid phase ignition-to-combustion transition, similar to the liquid phase combustion event shown in figure 6, and evaluate the alloy for this type of event. To perform the evaluation, the LTS heating procedure, a variant of a standard thermal analysis temperature scan technique, was adapted and modified for laser heating. Surface heating rates of approximately 100 to $200 \mathrm{~K} / \mathrm{min}$ were used. Experimental data were obtained for the oxygen pressure range of 1.72 to $6.89 \mathrm{MPa}$ (250 to $1000 \mathrm{psia}$ ). The results for a typical experiment are shown in figure 7. There are three major features in the waveform of figure 7. The first is the extreme nonparallelism between the surface (pyrometer) waveform and the interior (thermocouple) waveform. The second is the change 


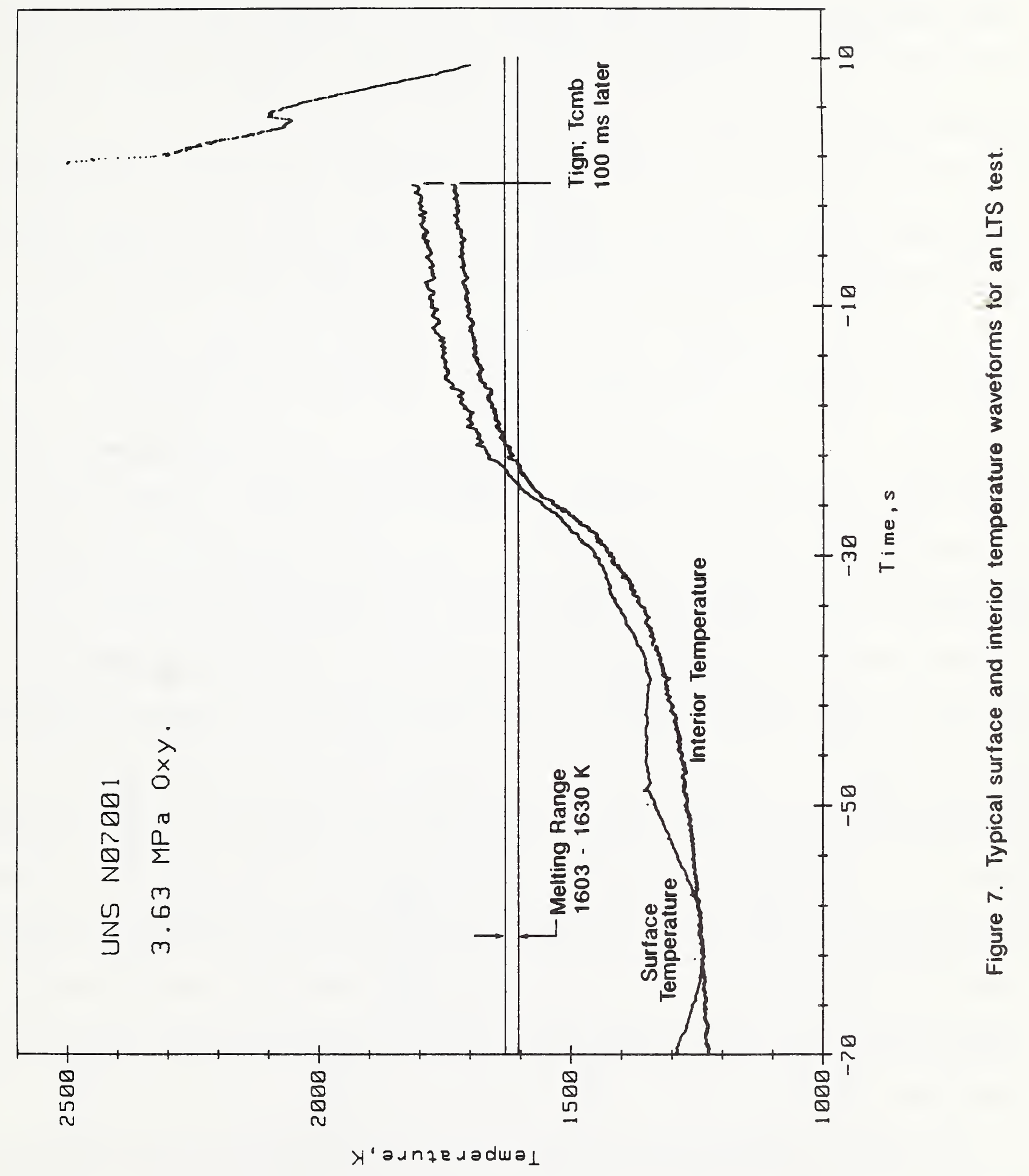


from a linear interior temperature waveform to a nonlinear waveform beginning at approximately $-51 \mathrm{~s}$. The third is the abrupt ignition with immediate combustion that occurred above the liquidus temperature. Negative time in our data indicates time prior to combustion. Not as obvious, due to compression of the data, are endothermic (constant temperature) features in the waveform. Several examples are shown in figure 8.

The extreme nonparallelism between the surface and interior temperature waveforms indicated that the pyrometer measurement was being severely affected by the optical properties of the oxide surface. Since the pyrometer was a two-color ratio instrument, the property that would introduce errors of the magnitude observed was non-linearity with wavelength of the surface emissivity. The shape of the surface temperature waveform indicates that the emissivity of the oxides would be a function of wavelength, temperature, and possibly oxide thickness, which was time-dependent. Because of the time dependency of the waveforms, the pyrometer could not be calibrated to eliminate the measurement error. Thus, the surface temperature waveforms cannot be used to obtain accurate values for $\mathrm{T}_{\text {ign }}$ and $\mathrm{T}_{\mathrm{cmb}}$. However, estimates of the range of the surface temperature values relative to the interior temperature can be obtained from several tests and from other materials which have been tested and have thermal properties similar to N07001. One such test which appears to give accurate surface temperature values for $T_{i g n}$ and $T_{c m b}$ is shown in figure 7. From the sources noted we estimate that the surface temperature at $T_{i g n}$ and $T_{c m b}$ would be 75 to $100 \mathrm{~K}$ higher than the interior temperature values.

At interior temperatures between 1250 to $1300 \mathrm{~K}$, the specimen began to rapidly autoheat, as shown in figure 7. Laser power was reduced in order to 


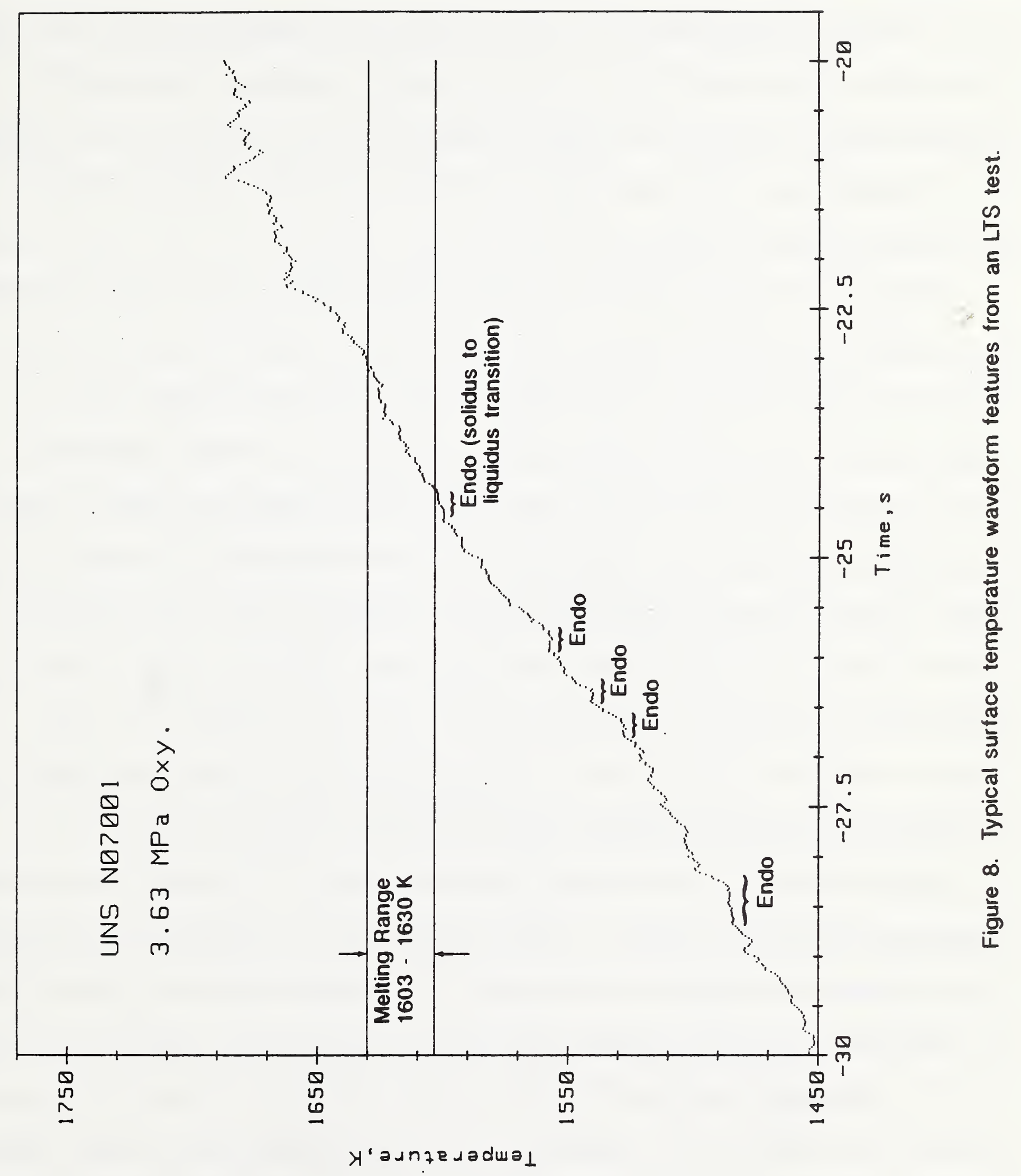


maintain the linear temperature ramp. However, the power reduction rate could not offset the accelerating temperature change until the interior temperature exceeded the liquidus temperature. At the solidus temperature, the oxidation rate increased significantly and a thick oxide layer began to form. The thick oxide layer, which impeded heat transfer from the surface to the interior oxidation zone, along with reduced external power, allowed the heating ramp to be re-established. The temperature continued to increase until an abrupt ignition-to-combustion event occurred.

Abrupt ignition-to-combustion events are thought to occur when the oxide layer cracks or spalls and exposes minimally oxidized material. The subsequent rapid oxidation in a geometry that has reduced radiant and convective heat loss may initiate a rapid melting and oxidation feedback mechanism that is observed as an abrupt ignition-to-combustion event. There are two potential sources for generating cracks and spallation in the oxide layer: stress induced by differences in the density between the alloy and product oxides, and stress from expansion of the liquefying alloy. Both mechanisms are apparently involved, but the latter was probably the most frequent mechanism, since combustion for the LTS heating procedure always occurred at temperatures greater than the liquidus temperature.

Small endothermic features were present in both the interior and surface temperature waveforms. Figure 8 shows examples of the endothermic features from a surface temperature waveform. Not all features are noted. Several of the features occur over a temperature range of $\pm 0.09 \mathrm{~K}$ ( \pm 1 digitizing leve1). This indicates that the effect covers the field of view of the pyrometer and dominates the temperature profile of that field of view. The sources of most of the endothermic features have not been determined; however, 
several are melting transitions of known oxides or of the alloy. There were indications that the source of some endothermic events may be associated with an acceleration of the rate of increase in specimen temperature, which was interpreted as an increase in oxidation rate of the material.

The ignition and combustion data for the LTS test are 1isted in table 2 and plotted in figures 9 and 10. Figure 9 shows the ignition temperatures as a function of oxygen pressure. Ignition always occurred at temperatures greater than the alloy liquidus temperature. The ignition-to-combustion transition occurred rapidly. Combustion was often concurrent with ignition, as shown in table 2. There was no tendency for abrupt ignition and combustion to develop at temperatures below the solidus temperature. Because there was no trend toward solid state ignition and combustion in the data, testing was halted at an oxygen pressure of $6.9 \mathrm{MPa}$ (1000 psi) in favor of thermal analysis (DTA) and ITS tests. The DTA tests were run to study the effect of the surface oxides on autoheating while the ITS tests were run to study the effect of autoheating on bulk specimens.

\section{Differential Thermal Analysis Studies}

The appearance of features in the temperature-time waveforms from the LTS tests, interpreted as endothermic and exothermic events, led to efforts to verify this interpretation. The approach was to utilize standard Differential Thermal Analysis (DTA) techniques and equipment and search for endothermic and exothermic events. Testing was carried out in flowing oxygen or helium at atmospheric pressure using 15 to $50 \mathrm{mg}$ specimens heated to temperatures greater than the liquidus temperature of the alloy. 
Table 2. LTS test series ignition and combustion temperatures.

\begin{tabular}{|c|c|c|}
\hline \multirow{2}{*}{$\begin{array}{c}\text { Pressure, } \\
\mathrm{MPa}\end{array}$} & \multicolumn{2}{|c|}{ Interior Temperature, $\mathrm{K}$} \\
\cline { 2 - 3 } & $\mathrm{T}_{\text {ign }}$ & $\mathrm{T}_{\mathrm{cmb}}$ \\
\hline \hline 1.779 & 1826 & 1840 \\
1.786 & 1805 & 1809 \\
1.806 & 1814 & 1821 \\
1.813 & 1828 & 1828 \\
3.523 & 1675 & 1675 \\
3.551 & 1741 & 1741 \\
3.565 & 1819 & 1819 \\
3.585 & 1734 & 1734 \\
3.634 & 1728 & 1730 \\
5.316 & 1766 & 1766 \\
5.357 & 1679 & 1679 \\
5.378 & 1769 & 1769 \\
5.399 & 1655 & 1655 \\
7.102 & 1675 & 1675 \\
7.184 & 1725 & 1725 \\
7.191 & 1775 & 1799 \\
7.295 & 1723 & 1725 \\
7.308 & 1727 & 1730 \\
\hline
\end{tabular}




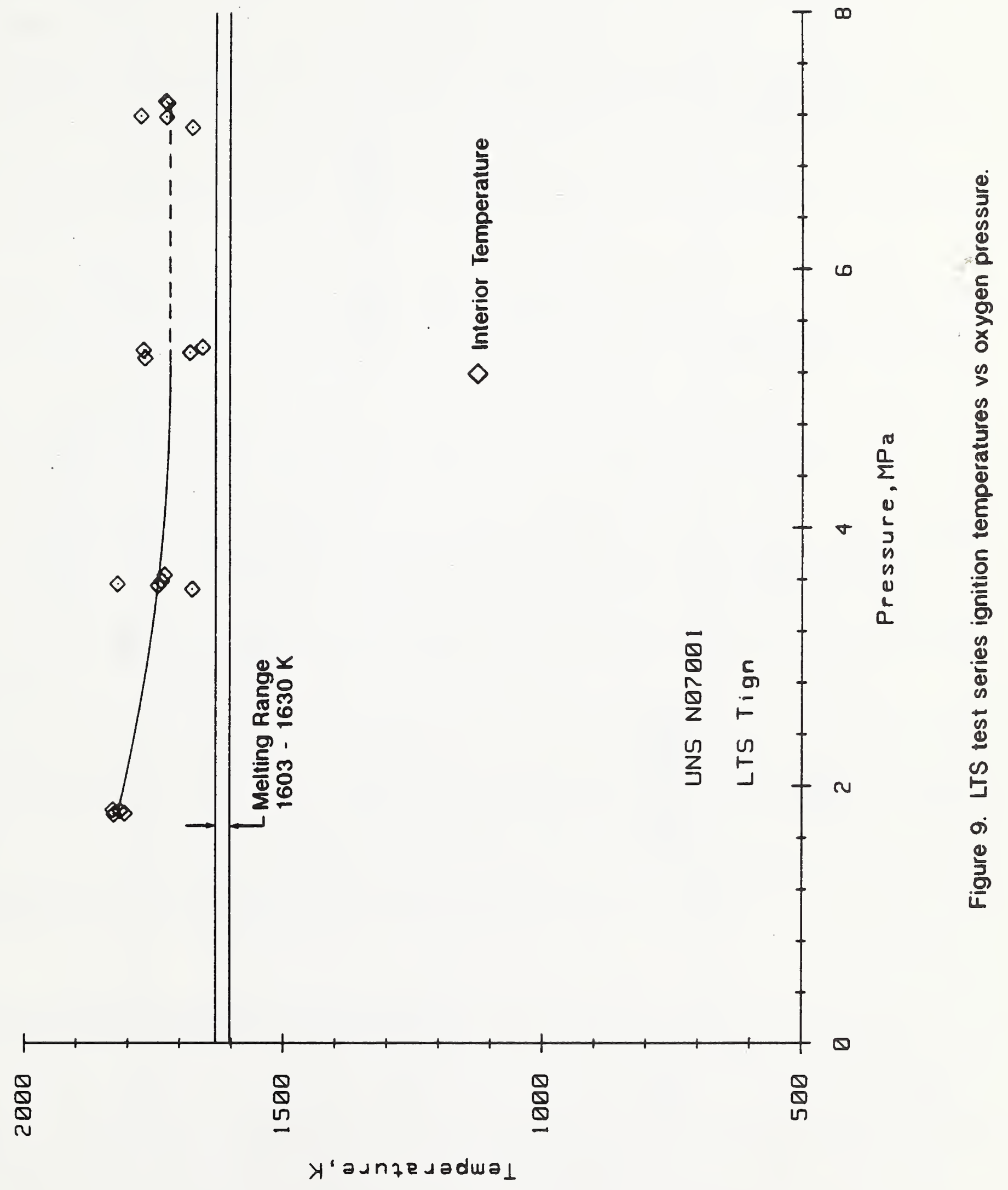




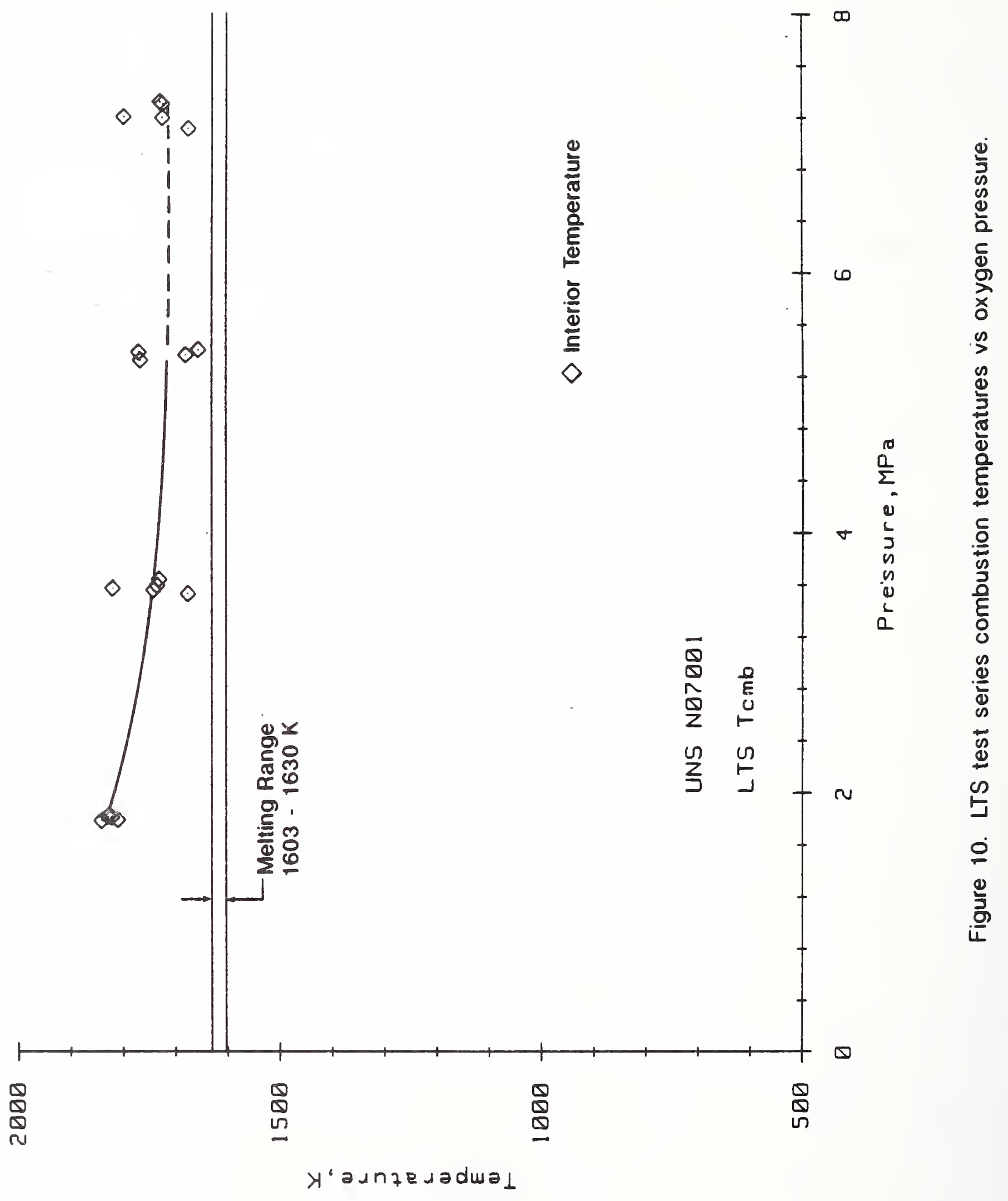


The tests in helium provided a baseline for comparison to the oxidation tests. These tests produced featureless thermographs except for the melting transition. However, the tests in oxygen demonstrated that the oxides produced during heating exhibited thermal activity, as shown in figure 11. Endothermic and exothermic transitions were present, but the temperatures of the individual transitions could not be firmly established because of their number and weakness. The weakness of the transitions was due to the small mass of responding material - a thin layer on the surface of a 15 to $50 \mathrm{mg}$ disk of alloy.

The presence of liquid and probably gaseous oxides was evident from the discoloration and eventual destruction of the aluminum oxide sample holders. Several investigators have postulated or observed the presence of liquid oxides during the high-temperature oxidation of alloys [5,6]. These investigators have also observed increased oxidation rates when liquid oxides were present. This tended to corroborate our observations of apparently increased oxidation rates at temperatures where some endothermic transitions occurred.

These studies also corroborate the existence of low-energy exotherms and the existence of at least one exothermic event as shown in figure 11 . These studies also provided an independent verification that the alloy does autoheat at temperatures below the solidus temperature of the alloy.

\section{Incremental Temperature Scan Tests}

The experiments to investigate the tendency of bulk alloy specimens to autoheat to destruction were performed using the ITS heating procedure. This procedure applied constant laser power to the top surface of the specimen. 


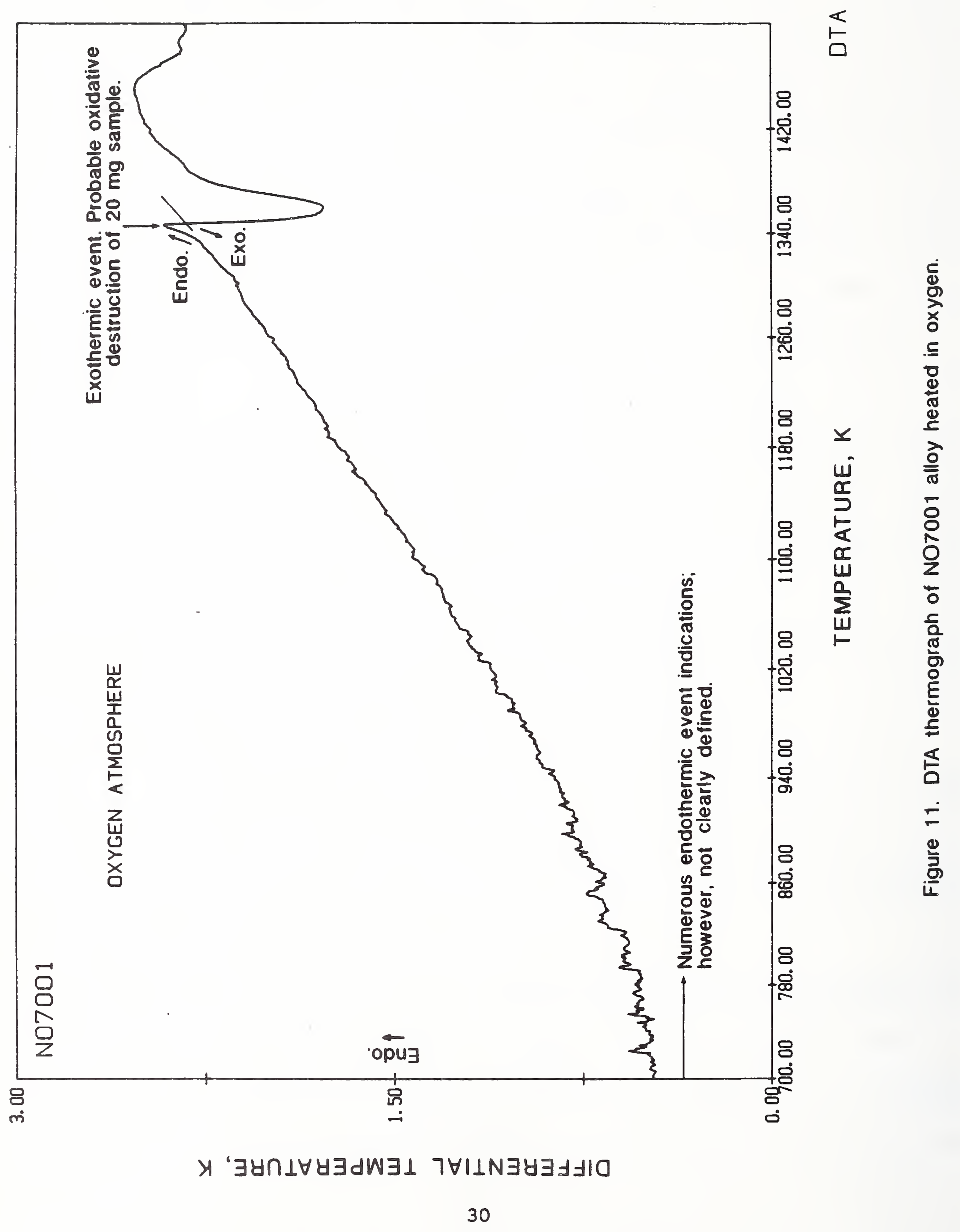


The power was increased at intervals after surface temperature equilibrium was established, until the specimen began to autoheat. The external heating rate was then held constant until autoheating ceased or combustion occurred.

Figure 12 shows the surface and interior temperature-time waveforms for a typical experiment.

Plotting of the interior temperature waveform in figure 12 was terminated where the next data point exceeded the valid temperature range of the thermocouple, $2040 \mathrm{~K}$. The surface temperature was monitored through combustion, which exceeded the temperature limits on the plot, and cool-down. Extreme non-parallelism existed between the surface and interior temperature waveforms. This indicated that problems were being encountered in measuring surface temperature in the ITS test mode as were encountered in the LTS test mode. Consequently, the surface temperature waveform could not be used to obtain accurate values of $\mathrm{T}_{\mathrm{sp}}, \mathrm{T}_{\mathrm{eo}}$, and $\mathrm{T}_{1 \mathrm{gn}}$.

Endothermic features were present in both the interior and surface temperature waveforms. However, these features were significantly smaller than those encountered for many other materials, see [1,2] for examples. The source of these small features, several of which are shown in figure 13, did not appear to affect the rate of increase in temperature as appeared to be the case with a number of other alloys $[1,2]$.

Due to the unsuitability of the surface temperature waveform, the interior temperature waveform was used to determine the onset of spontaneous ignition and enhanced oxidation. However, both the surface and interior temperature-time waveforms were used to determine the onset of ignition and combustion. 


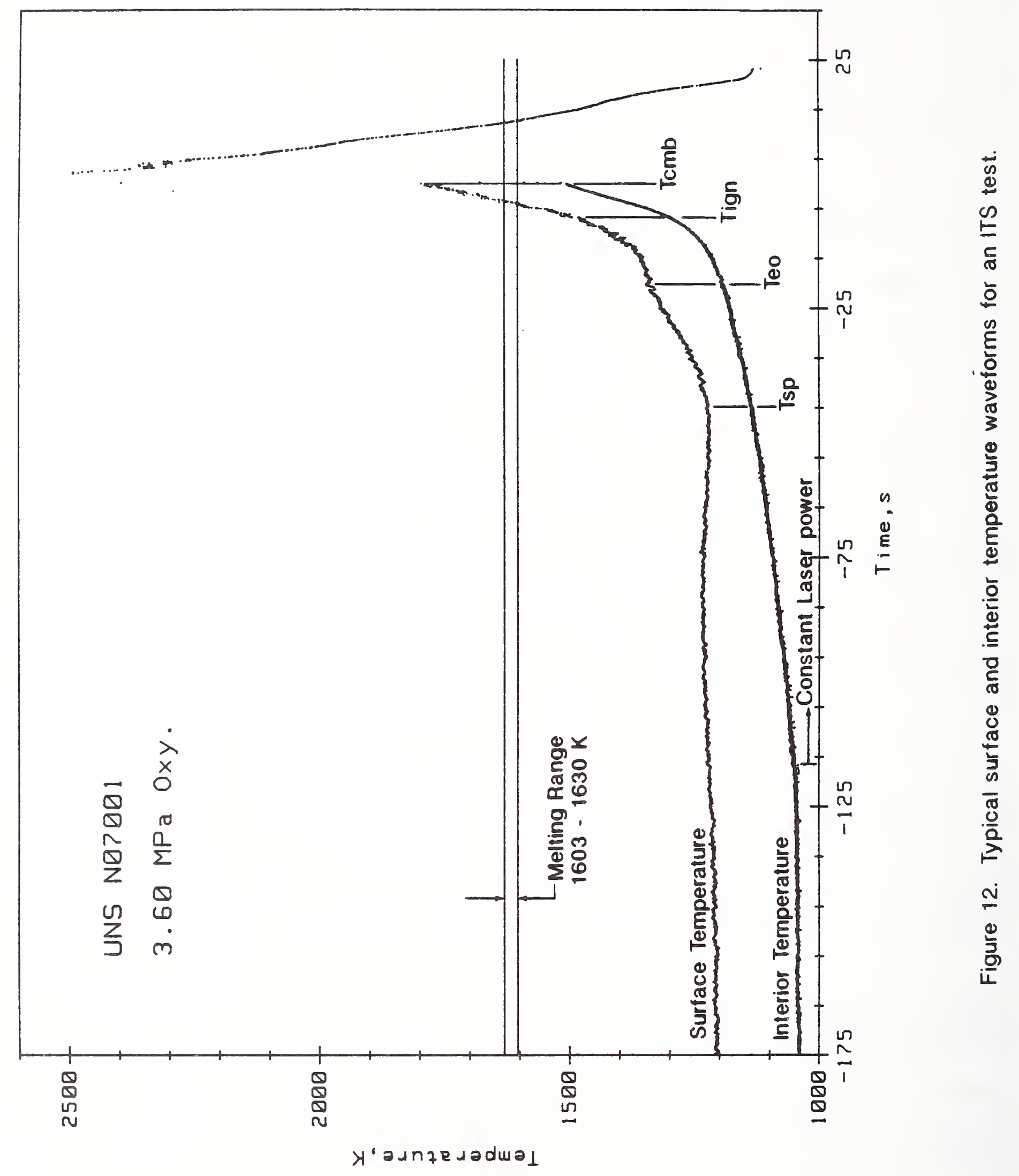


Figure 13, an expansion of a section of figure 12, shows the development of combustion in greater detail. The linear heating rate from $-80 \mathrm{~s}$ to $\mathrm{T}_{\mathrm{sp}}$ shown on the interior temperature waveform of figure 13 was not due to oxidation heating. Instead, it was due to the changing absorptivity of the oxide surface. The absorptivity heating effect was differentiated from oxidation heating by tests using preoxidized specimens. These tests demonstrated that autoheating by oxidation generated a curvilinear temperature-time waveform rather than a linear temperature-time waveform as observed from $-80 \mathrm{~s}$ to $\mathrm{T}_{\mathrm{sp}}$. At $\mathrm{T}_{\mathrm{sp}}$ the shape of the interior temperature-time waveform changed from linear to curvilinear indicating that oxidation heating was beginning to influence the heating rate. The rate of increase in temperature immediately after $\mathrm{T}_{\mathrm{sp}}$ was approximately $1.9 \mathrm{~K} / \mathrm{s}$ and increased to approximately $2.6 \mathrm{~K} / \mathrm{s}$ at $\mathrm{T}_{00}$. The curvature of the waveform section from $\mathrm{T}_{\mathrm{sp}}$ to $\mathrm{T}_{\mathrm{eo}}$ is somewhat difficult to observe due to the graph scale and the effects of several endothermic regions, which are noted on the plot. Small curvature within a waveform section was detected by orthogonal polynomial curve fits with the best fit selected by analysis of variance techniques. $\mathrm{T}_{\mathrm{sp}}$ was chosen as the beginning of a clearly established curvature of the interior temperature-time waveform.

$\mathrm{T}_{\text {eo }}$ was chosen as the beginning of a clearly established abrupt change in curvature of the interior temperature-time waveform. This occurred, as noted on the plot, in a region where several endotherms have occurred. Curve fits were used to establish that the slope at $T_{\text {eo }}$ changed from approximately 2.6 $\mathrm{K} / \mathrm{s}$ to approximately $3.7 \mathrm{~K} / \mathrm{s}$. Though speculative, it is though that $\mathrm{T}_{e o}$ may lie in a temperature region where the oxidation kinetics change from protective to nonprotective oxidation. 


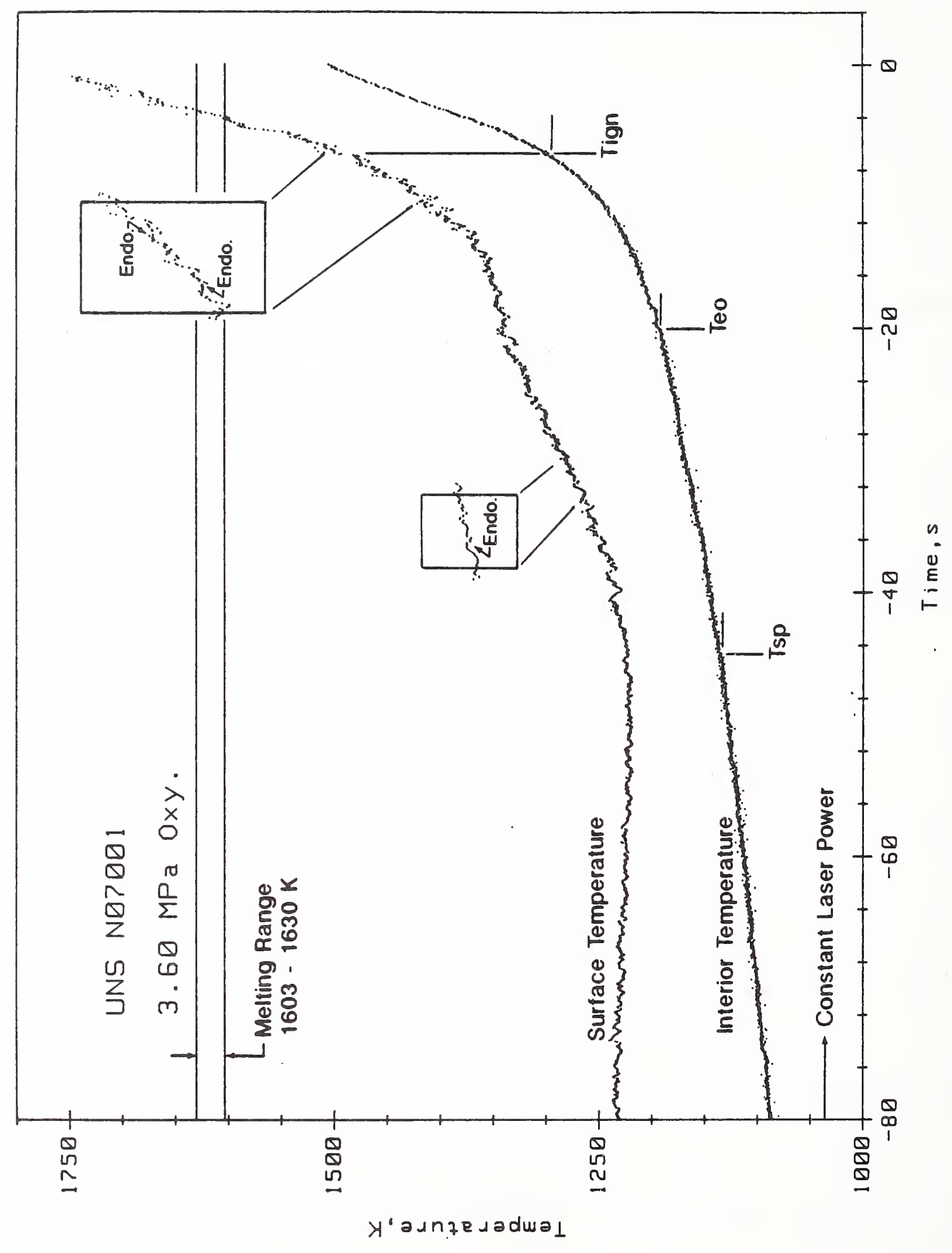

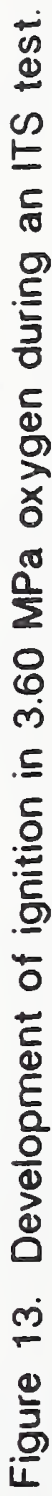


After $T_{\text {eo }}$ occurs, the slope of the temperature-time waveform increases rapidly to a limiting value at $\mathrm{T}_{\mathrm{ign}}$. It is desirable to use the surface temperature-time waveform to determine $\mathrm{T}_{\text {ign }}$, since the response time of the pyrometer was much faster than the thermocouple. However, due to the surface temperature measurement problems, both the interior and surface temperaturetime waveforms were used. As a result, the compromise that had to be reached between the two waveforms leads to a $\mathrm{T}_{\text {ign }}$ value at a point on the interior temperature waveform where a small curvature could remain (fig. 13). However, the curvature was slight or non-existent for higher oxygen pressures (fig. 14). Because of the effect of oxide surface emissivity on the shape of the surface temperature waveform and the small remaining curvature that could result in the interior temperature waveform at the selected $T_{\text {ign }}$ value, this parameter may not always exactly fit our definition of $T_{1 g n}$. However, it was considered that the value of $\mathrm{T}_{1 \mathrm{gn}}$ is probably within several percent of the definition value.

Figure 14 shows the development of ignition at high oxygen pressure, 10.47 MPa (1519 psia). The higher oxygen pressure has increased the oxidation rate of the alloy and created a thicker oxide layer. The thicker oxide layer reduced the measurement problems at the higher oxygen pressure, however, some measurement uncertainty remained. The example shown was among the best surface measurement results obtained for this alloy. The nominal $80 \mathrm{~K}$ difference between the surface and interior temperature-time waveforms was also close to the difference values obtained for other nickel-based alloys. Figure 14 also shows that combustion, in the form of hot spots, could develop while the surface temperature was below the solidus temperature. 


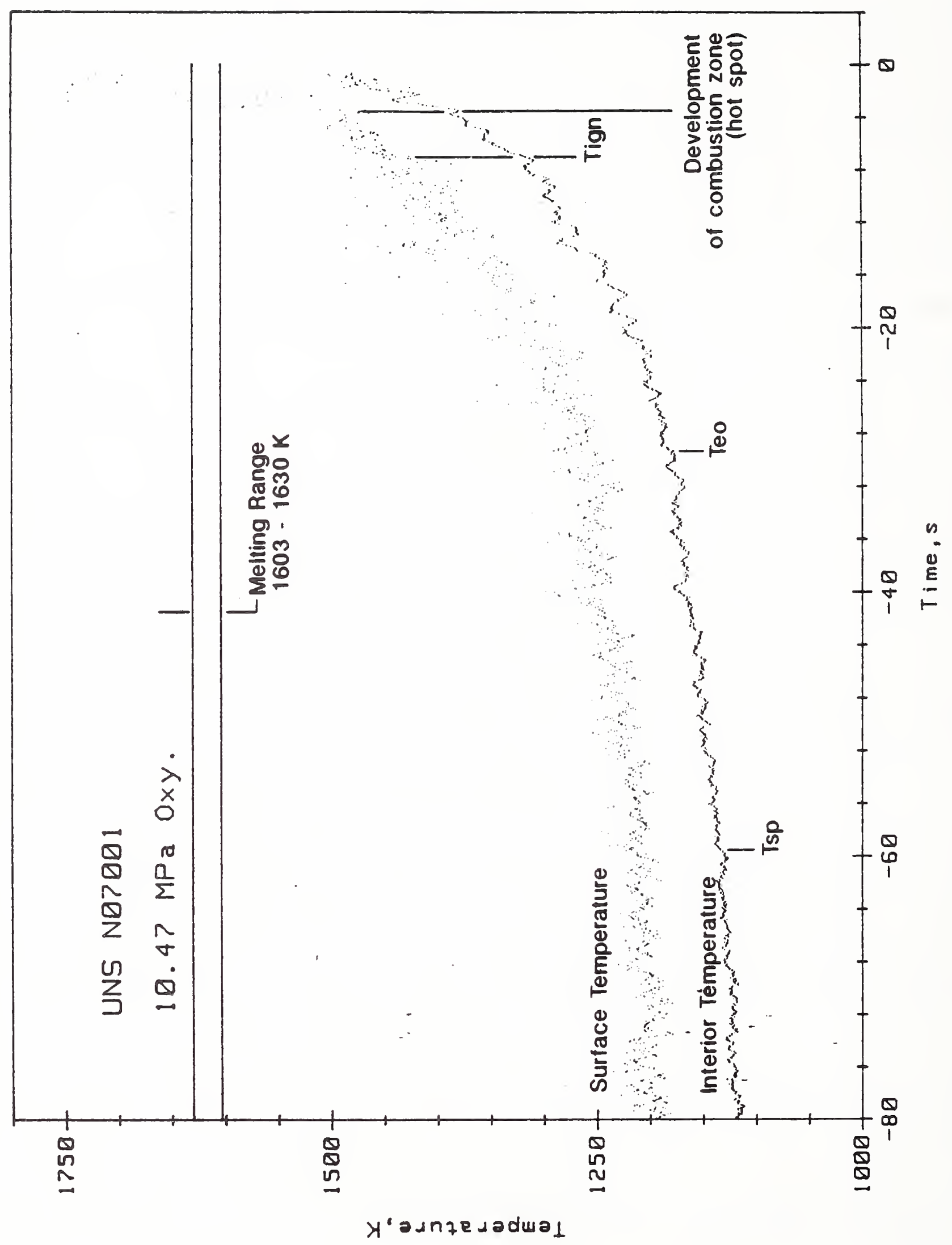

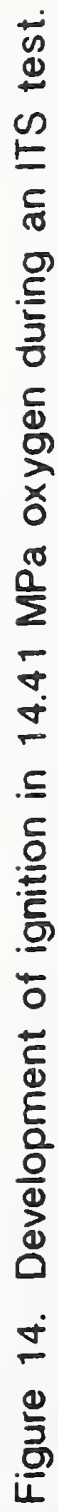


Table 3 lists the values of the ignition parameters. These parameters are plotted in figures 15 through 18. The data have been fitted to linear least-squares curves so that the trends in data with respect to oxygen pressure could be established. The coefficients of these curves are listed in table 4. The values of $\mathrm{T}_{\mathrm{sp}}, \mathrm{T}_{e 0}$, and $\mathrm{T}_{\text {ign }}$ decrease with increasing oxygen pressure over the full range of the data. The high pressure tests have been used to establish an estimate of the surface temperatures. It was estimated that the surface temperature was probably $80 \mathrm{~K}$ greater than the interior temperature.

\section{Data Accuracy}

The surface temperature values of $\mathrm{T}_{\mathrm{sp}}, \mathrm{T}_{\mathrm{eo}}$, and $\mathrm{T}_{\mathrm{ign}}$ are not presented in this report due to the apparent large inaccuracy of the surface measurement.

The interior temperature data were obtained from thermocouples made from material certified to conform to IPTS-68. The thermocouple thermoelectric voltage, $E(T)$, was converted to temperature from a polynomial derived from the temperature-E(T) table from NBS Monograph 125 [7]. The maximum deviation of the polynomial value from the table value, in the range of the data, was 0.5 K. The largest uncertainty in the thermocouple data was generated by the digitizers. This equipment has a stated accuracy of $0.15 \%$ full scale, which was $0.15 \mathrm{mV}$ in the $\mathrm{E}(\mathrm{T})$ value. At $1000 \mathrm{~K}$, the error due to the digitizer would be approximately $14 \mathrm{~K}$. However, the thermocouple/digitizer combination consistently detected the onset of alloy melting at $1603 \mathrm{~K}$ to within $\pm 6 \mathrm{~K}$ or better with no deviations greater than $\pm 10 \mathrm{~K}$. 
Table 3. ITS test series spontaneous ignition, enhanced oxidation, ignition and combustion temperatures.

\begin{tabular}{|c|c|c|c|c|}
\hline $\begin{array}{c}\text { Pressure, } \\
\mathrm{MPa}\end{array}$ & $\mathrm{T}_{\text {sp }}, \mathrm{K}$ & $\mathrm{T}_{\text {eo }}, \mathrm{K}$ & $\mathrm{T}_{\text {ign }}, \mathrm{K}$ & $\mathrm{T}_{\text {cmb }}, \mathrm{K}$ \\
\cline { 2 - 5 } & Interior & Interior & Interior & Surface \\
\hline 1.793 & 1109 & 1160 & 1288 & 1933 \\
1.813 & 1157 & 1188 & 1303 & 1921 \\
1.820 & 1107 & 1176 & 1339 & 1772 \\
1.827 & 1102 & 1122 & 1248 & 1849 \\
3.544 & 1119 & 1150 & 1271 & 1909 \\
3.565 & 1140 & 1207 & 1268 & 1758 \\
3.571 & 1115 & 1176 & 1292 & 1792 \\
3.599 & 1086 & 1181 & 1283 & 1715 \\
3.599 & 1135 & 1191 & 1296 & 1762 \\
5.240 & 1111 & 1133 & 1295 & 1771 \\
5.323 & 1139 & 1190 & 1353 & 1765 \\
5.337 & 1099 & 1157 & 1292 & 1695 \\
5.337 & 1119 & 1182 & 1384 & 1779 \\
5.357 & 1102 & 1144 & 1335 & 1674 \\
5.743 & 1118 & 1184 & 1289 & 1683 \\
7.171 & 1140 & 1155 & 1324 & 1756 \\
7.191 & 1122 & 1182 & 1316 & 1739 \\
7.302 & 1157 & 1187 & 1274 & 1597 \\
7.315 & 1115 & 1168 & 1258 & 1691 \\
8.639 & 1130 & 1158 & 1233 & 1549 \\
9.060 & 1138 & 1170 & 1266 & 1426 \\
10.473 & 1132 & 1177 & 1308 & 1472 \\
11.018 & 1084 & 1126 & 1204 & 1509 \\
11.025 & 1158 & 1173 & 1308 & 1472 \\
12.211 & 1137 & 1185 & 1243 & 1376 \\
12.218 & 1176 & 1183 & 1257 & 1422 \\
12.349 & 1101 & 1140 & 1255 & 1596 \\
12.369 & 1135 & 1216 & 1349 & 1687 \\
12.411 & 1138 & 1213 & 1322 & 1429 \\
13.831 & 1066 & 1085 & 1150 & 1429 \\
13.907 & 1096 & 1131 & 1221 & 1463 \\
13.934 & 1106 & 1159 & 1210 & 1468 \\
\hline & & & & \\
\hline
\end{tabular}




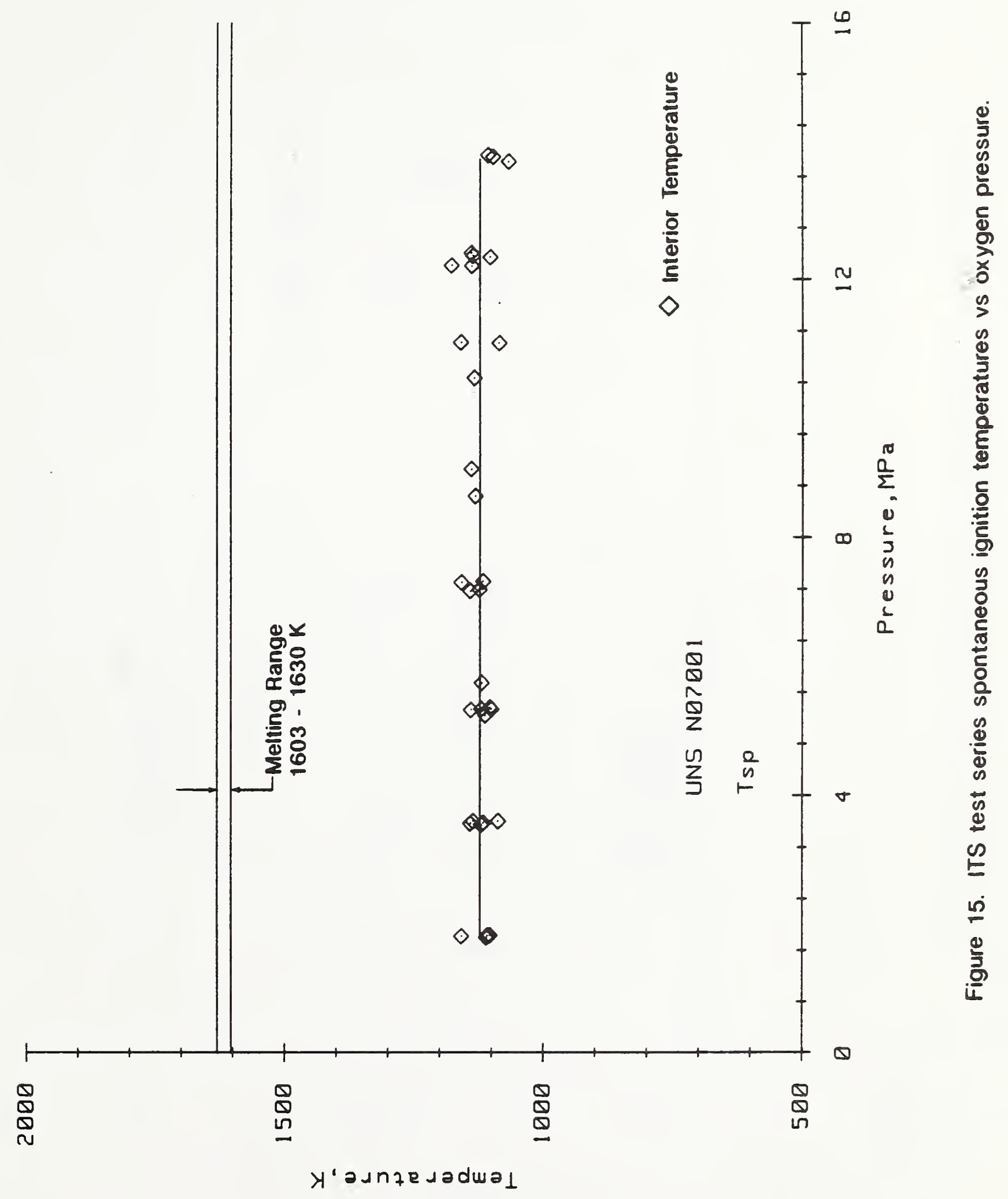




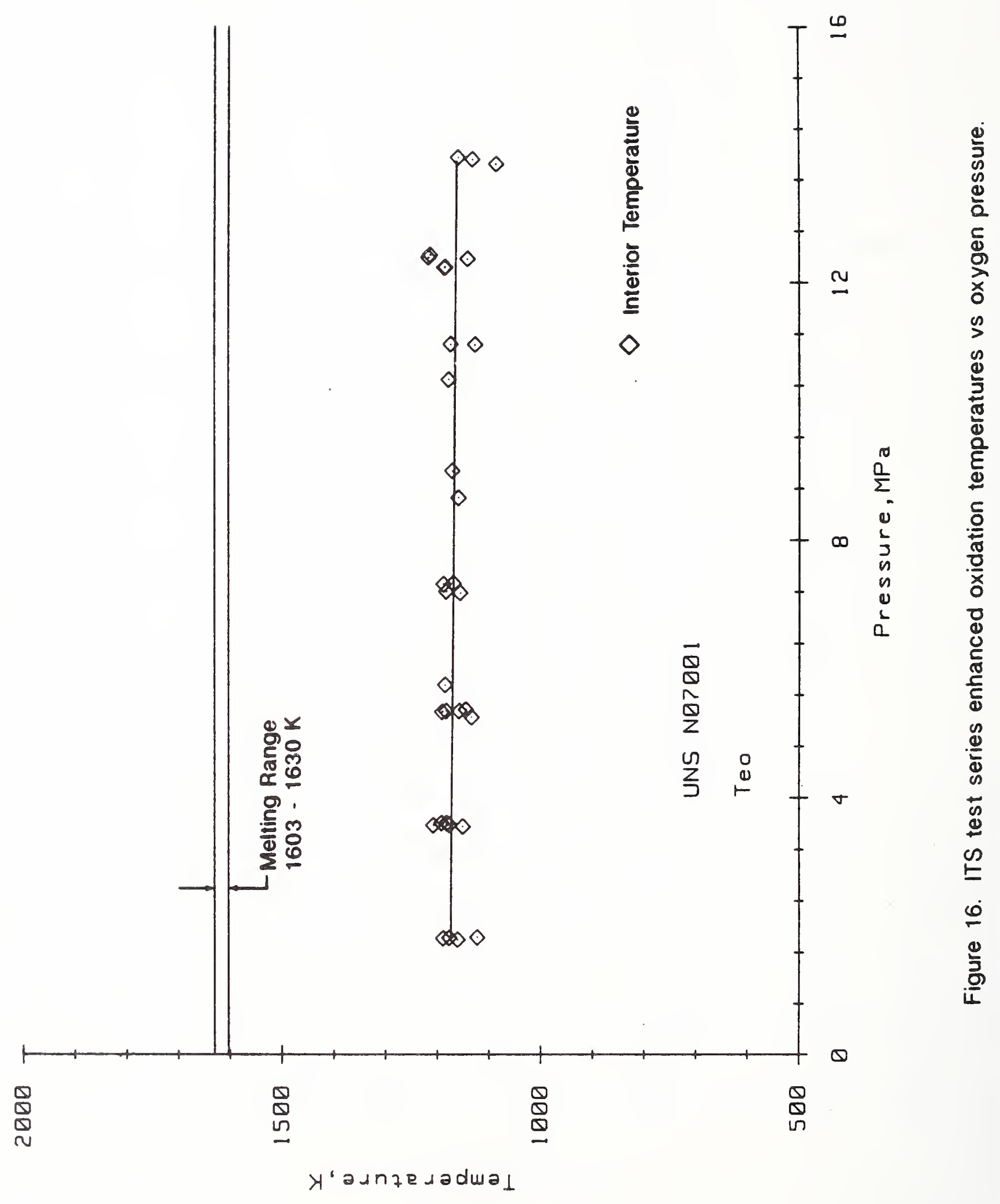




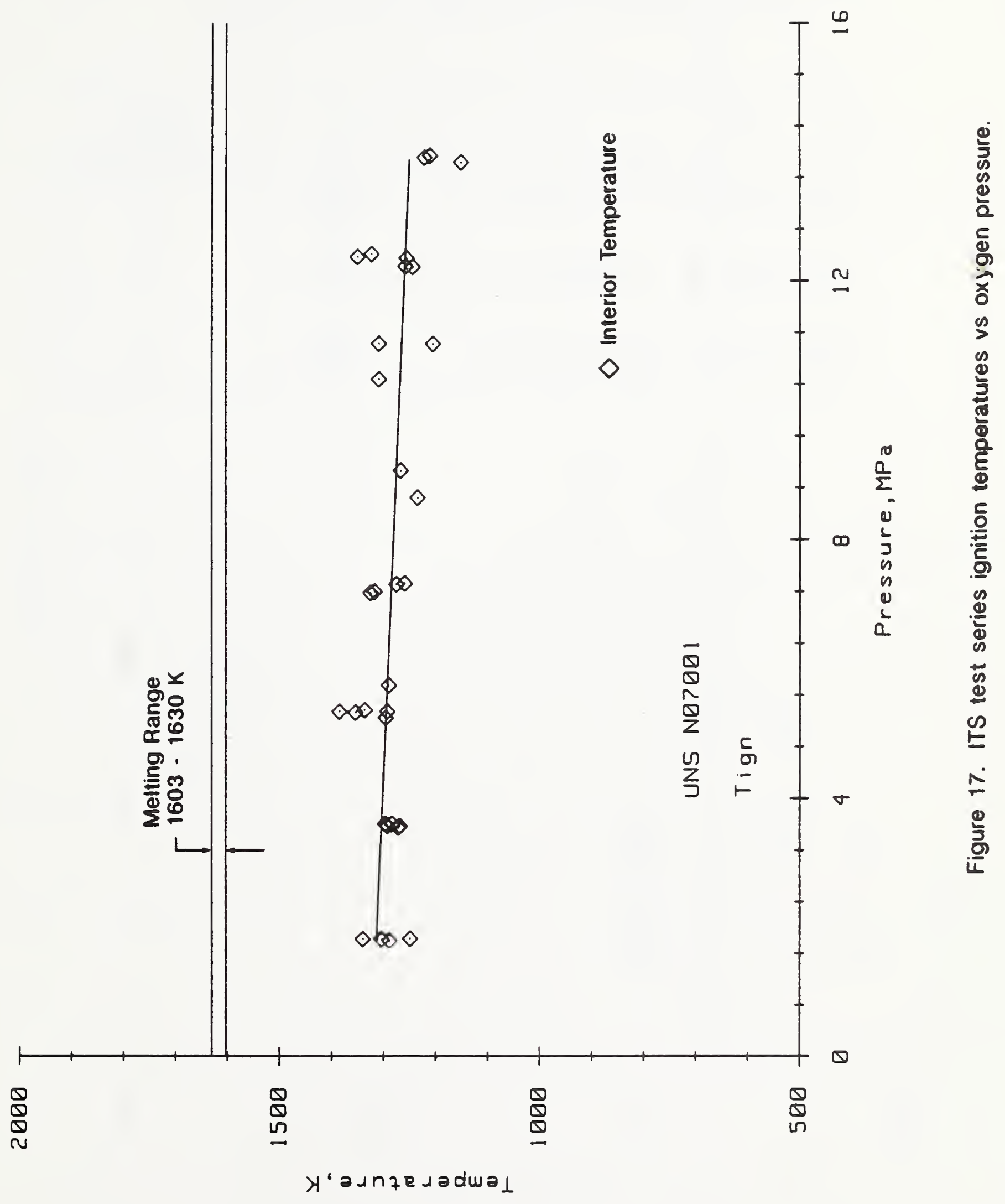




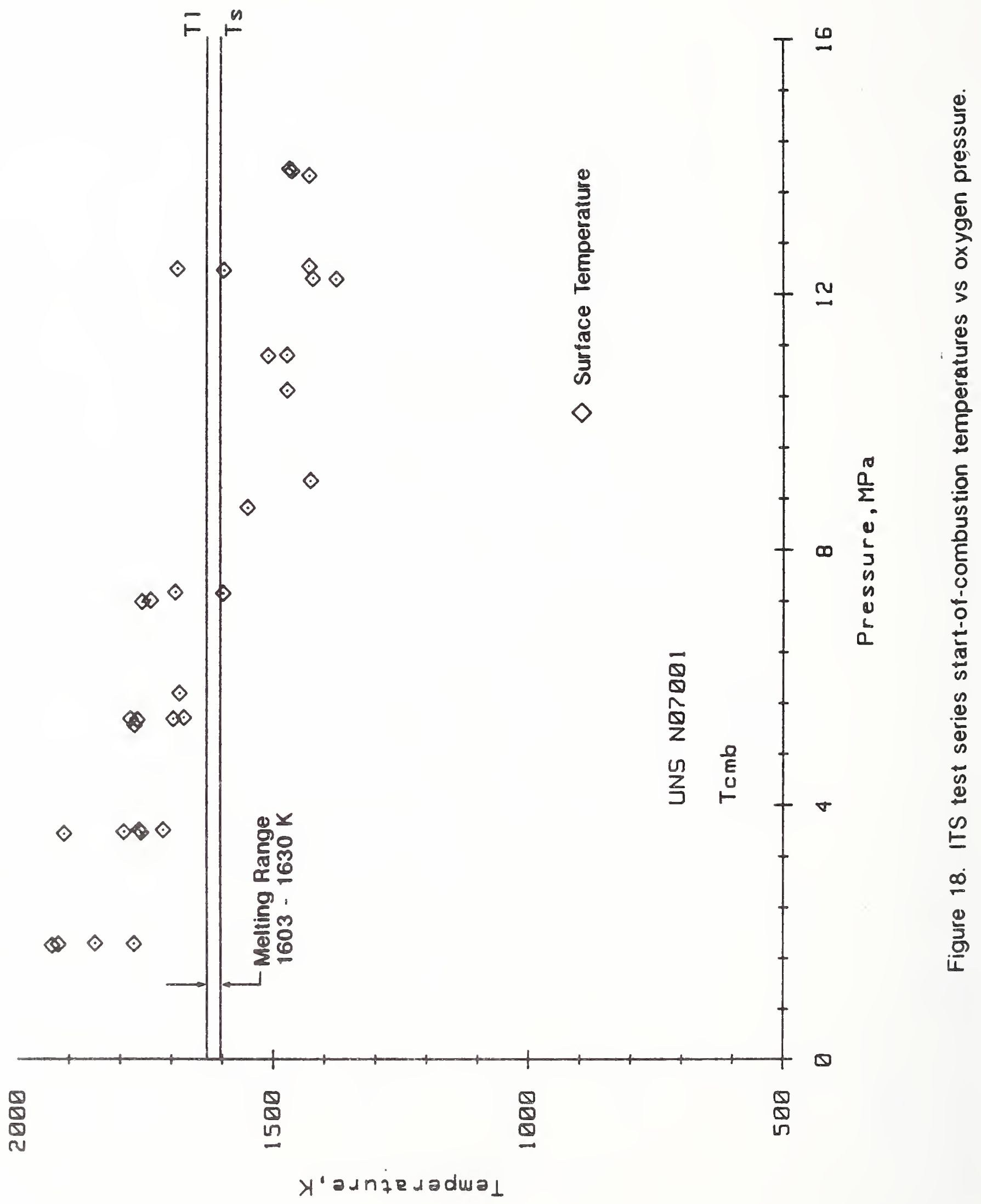


Table 4. Linear least-squares curve fit coefficients for the ITS ignition parameter data shown in Figures 15, 16, and 17.

\begin{tabular}{|c|l|c|c|}
\hline $\begin{array}{c}\text { Ignition } \\
\text { Parameters }\end{array}$ & Waveform & $\mathrm{A}_{1}$ & $\mathrm{~A}_{2}$ \\
\hline \hline $\mathrm{T}_{\mathrm{sp}}$ & Interior & $1.121 \mathrm{E}+03$ & $-2.519 \mathrm{E}-02$ \\
$\mathrm{~T}_{\mathrm{eo}}$ & Interior & $1.175 \mathrm{E}+03$ & $-1.031 \mathrm{E}+00$ \\
$\mathrm{~T}_{\text {ign }}$ & Interior & $1.321 \mathrm{E}+03$ & $-5.185 \mathrm{E}+00$ \\
\hline
\end{tabular}




\section{CONCLUSIONS}

The LTS tests and data indicated that millisecond ignition to combustion transitions would not occur at oxygen pressures up to $6.9 \mathrm{MPa}$. In addition, the trend of the ignition and combustion temperature data versus oxygen pressure was flat from 5.2 to $6.9 \mathrm{MPa}$. That trend would indicate that there would be no tendency for this alloy to have abrupt solid phase ignition to combustion transitions for oxygen pressures reasonably greater than $6.9 \mathrm{MPa}$. The LTS tests and data also indicated that the solid phase oxidation rate of the alloy was sufficient for the alloy to autoheat to destruction in our reduced heat loss experimental setup. The autoheating usually began at an interior temperature that ranged from approximately 1250 to $1290 \mathrm{~K}$. Since the interior temperature was on the order of $80 \mathrm{~K}$ less than the surface temperature, the 1250 to $1290 \mathrm{~K}$ range matches well with the exotherm at approximately $1340 \mathrm{~K}$ from the DTA runs.

The ITS interior temperature data established that under the appropriate low heat loss conditions, the oxidation rate of the alloy was sufficient to cause autoheating to combustion to occur from temperatures below the alloy solidus temperature. Combustion zones (hot spots) began to develop at oxygen pressures of $8.62 \mathrm{MPa}$ and greater. General combustion did not begin until the surface temperatures were greater than the alloy liquidus temperature at all oxygen pressures. However, this alloy may have a "sudden failure" characteristic (millisecond transition from ignition to general combustion) at oxygen pressures greater than our maximum test pressure of $13.9 \mathrm{MPa}$.

The rate at which general combustion developed after ignition increased three-fold from an oxygen pressure of 1.7 to $13.9 \mathrm{MPa}$ clearly indicating that the alloy oxidation rate was oxygen pressure sensitive. The temperature at 
which $\mathrm{T}_{\mathrm{sp}}, \mathrm{T}_{\theta 0}$, and $\mathrm{T}_{\mathrm{ign}}$ occurred decreased with increasing oxygen pressure. That trend indicates that these parameters are a function of the oxidation rate of the material and that the oxidation rate increased more rapidly with increasing oxygen pressure than the cooling rate.

\section{FUTURE EFFORT}

The program of which this study is a part has recently been expanded to include the direct determination of oxidation rates of selected alloys. To achieve this, a thermogravimetric apparatus (TGA) is being constructed. The apparatus will use a microgram balance housed in a pressure chamber to directly measure the oxidation rate. The system has been designed to operate to pressures of $34.5 \mathrm{MPa}(5000 \mathrm{psia}$ ) and to temperatures greater than $1700 \mathrm{~K}$. This equipment will be used to generate oxidation rate data as a function of time, temperature, and oxygen pressure. From these data, the $\mathrm{Q}_{(\mathrm{chem})}$ curve can be determined. Once the $\mathrm{Q}_{(\mathrm{chem})}$ curve is known, computer modeling of system designs and potential abnormal operating conditions can be accomplished and the most appropriate materials chosen for a given design.

\section{ACKNOWLEDGMENT}

The authors express their appreciation to John G. Austin, Jr., retired, and Richard T. Congo, technical representatives, George C. Marshall Space Flight Center, for their many valuable contributions to this study and the overall program and to the George C. Marshall Space Flight Center for funding. 


\section{REFERENCES}

[1] Bransford, James W., Billiard, Phillip A., Hurley, James A., McDermott, Kathleen M., and Vazquez, Isaura, Ignition Characteristics of the Iron Based Alloy UNS S66289 in Pressurized Oxygen, NISTIR 88-3904, Nov. 1988.

[2] Bransford, James W., Billiard, Phillip A., Hurley, James A., McDermott, Kathleen M., and Vazquez, Isaura, Ignition Characteristics of the Nickel-Based Alloy N07718 in Pressurized Oxygen, NISTIR 89-3911, April 1989.

[3] Mellor, A.M., Heterogeneous Ignition of Metals: Models and Experiment, Ph.D. Thesis, Princeton University, Princeton, N.J., 1968.

[4] Bransford, James W., Billiard, Phillip A., Hurley, James A., McDermott, Kathleen M., and Vazquez, Isaura, The Development of Combustion from Quasi-Stable Temperatures for the Iron Based Alloy UNS S66286. ASTM SP 986, pp. $146-157$ (1988).

[5] Brenner, S.S., Catastrophic Oxidation of Some Molybdenum-Containing Alloys, J. Electrochem. Soc., Vol. 102, No. 1, p. 16 (1954).

[6] Rathenau, F.W. and Meijering, J.L., Rapid Oxidation of Metals and Alloys in the Presence of $\mathrm{MoO}_{3}$, Metallurgia, Vol. 42, p. 157 (1950).

[7] Thermocouple Reference Tables Based on the IPTS-68, Nat. Bur. Stand. Monograph 125. 


\section{BIBLIOGRAPHIC DATA SHEET}

\section{TITLE AND SUBTITLE}

IGNITION CHARACTERISTICS OF THE NICKEL-BASED ALLOY UNS NO7OOI IN PRESSURIZED OXYGEN

5. AUTHOR(S)

James W. Bransford, Phillip A. Billiard

6. PERFORMING ORGANIZATION (IF JOINT OR OTHER THAN NIST, SEE INSTRUCTIONS)

U.S. DEPARTMENT OF COMMERCE

NATIONAL INSTITUTE OF STANDARDS AND TECHMOLOQY

BOULDER, COLORADO $80303-3328$

9. SPONSORIMG ORGANIZATION NAME AND COMPLETE ADDRESS (STREET, CITY, STATE, ZIP)

NASA/George C. Marshal1 Space Flight Center

George C. Marshall Space Flight Center, AL 35812

\section{SUPPLEMENTARY NOTES}

11. ABSTRACT (A 200-WORD OR LESS FACTUAL SUMMARY OF MOST SIGNIFICANT INFORMATION. IF DOCUMENT INCLUDES A SIGNIFICANT BIBLIOGRAPHY OR UTERATURE SURVEY, MENTION IT HERE.)

The development of ignition and combustion in pressurized oxygen atmospheres was studied for the nickel-based alloy UNS N07001. Ignition of the alloy was achieved by heating the top surface of a cylindrical specimen with a continuous-wave $\mathrm{CO}_{2}$ laser. Two heating procedures were used. In the first, laser power was adjusted to maintain an approximately linear increase in surface temperature. In the second, laser power was periodically increased until autoheating (self-heating) was established. It was found that the alloy would autoheat to combustion from temperatures below the solidus temperature. In addition, the alloy had a tendency to develop combustion zones (hot spots) at high oxygen pressures when the incremental (step) heating test mode was used. Unique points on the temperature-time curves that describe certain events are defined and the temperatures at which these events occur are given for the oxygen pressure range of 1.72 to $13.8 \mathrm{MPa}$ (250 to $2000 \mathrm{psia}$ ).

\section{KEY WORDS (6 TO 12 ENTRIES; ALPHABETICAL ORDER; CAPITALIZE ONLY PROPER NAMES; AND SEPARATE KEY WORDS BY SEMICOLONS)}

alloys; combustion; ignition; ignition temperature; metal; nickel alloy; oxygen; oxygen compatibility 


